\title{
Sulfonated graphenes: Efficient solid acid catalyst for the
}

2

3

4

5

6

$7{ }^{a}$ Laboratorio de Investigación en Catálisis y Procesos (LICAP) - Universidad del Valle,

8 Ciudad Universitaria Meléndez, Calle 13 \# 100-00, Cali-Colombia.

$9{ }^{b}$ Institut de Chimie des Milieux et Matériaux de Poitiers (ICM2P), UMR 7285 CNRS, 4

10 Rue Michel Brunet, Bâtiment B27, 86073, Poitiers Cedex-France.

$11{ }^{c}$ Grupo Catálisis, Departamento de Química, Universidad del Cauca, Carrera 3 No. 3N-

12 100, Popayán-Colombia.

$13 *$ Corresponding author: julian.urresta@correounivalle.edu.co (Julian Urresta)

14 miranda.cristian@ correounivalle.edu.co (Cristian Miranda)

15

16

17

18

19

20

21

\section{glycerol valorization}




\section{Abstract}

23 Heterogeneous acid catalysts were obtained based on the functionalization of reduced

24 graphene oxide. The synthesis involves i) the obtaining of graphene oxide by the modified

25 Hummers method ii) the reduction of graphene oxide by three different routes, through the

26 use of hydrazine dihydrochloride, $\mathrm{Zn} / \mathrm{HCl}$ and ascorbic acid, and iii) the grafting of sulfonic

27 groups in the surface of graphene oxides with 4-diazonium benzenesulfonate. These solids

28 were characterized and evaluated in the etherification of glycerol with tert-butyl alcohol,

29 finding in general glycerol conversions higher than those obtained with a sulfonic resin

30 (Amberlyst $^{\circledR}$ 15). In addition, the selectivity depends on the reduction route used to obtain

31 the catalyst; A larger amount of oxygen groups remaining after the reduction, helps the

32 formation of poly-substituted ethers. These solids also showed stability in their use,

33 converting them into highly efficient catalysts in the valorization of glycerol.

34

35 Key words: Reduced sulfonated graphene oxide, ascorbic acid reduction, glycerol 36 etherification, tert-butyl alcohol, glycerol ethers.

37

38

39

40

41

42 


\section{Introduction}

47 The large production of biodiesel has increased the production of glycerol, which is

48 a byproduct of this process. According to estimates, glycerol production will be six times

49 higher than global demand within a few years from now [1,2]. The glycerol conversion into

50 value-added products is thus an alternative for glycerol disposal and its surplus problem.

51 One promising way to valorize this polyol is through its conversion into glycerol ethers,

52 which can then be used as oxygenated fuel additive, intermediates in the pharmaceutical

53 industry and non-ionic surfactants [3-5]. The etherification of glycerol with isobutene or

54 tert-butyl alcohol allows obtaining different ethers depending on the degree of substitution.

55 For applications of these ethers as oxygenated additives, poly-substituted ethers ( $d i$ and tri-

56 ethers) are preferred due to their physical-chemical properties that are compatible with fuel

57 formulations, while the mono-ether is not suitable for this use due to its low solubility in

58 diesel [6].

59 The synthesis of glycerol tert-butyl ethers using isobutene has been extensively

60 investigated [7-10]. Yet it requires high pressures to ensure contact with glycerol.

61 Additionally, isobutene is separated as a vapor stream at the outlet of the reactor and must

62 be recompressed before recycling, which is another drawback of the process [11]. The use

63 of tert-butyl alcohol as an etherifying agent has been less studied. The etherification

64 between glycerol and tert-butyl alcohol can be catalyzed by acids. When this type of

65 catalysis and tert-butyl alcohol is used as an etherifying agent, water is obtained as a by-

66 product, which implies that the selected catalyst must be active in the presence of water

67 and, at the same time, the presence of this by-product can alter the equilibrium of the

68 formation of the glycerol poly-substituted ethers [12]. 
70 corrosion and environmental issues. These can be overcome by using solid acid catalysts

71 such as acid ion-exchange resin, but these have a poor thermal stability [14]. Zeolites are a

72 family of microporous minerals that feature important Brønsted acidy and high thermal

73 stability $[14,15]$. The use of zeolites in the glycerol etherification has recently allowed to

74 deduce that shape selective and confinement properties can drive activity, selectivity and

75 stability of the catalytic process [16].

76 Carbon materials are attractive metal-free, stable, cheap, and recyclable catalysts

77 that allow in any cases to achieve green and sustainable catalytic transformations [17].

78 Solid acid catalysts prepared from functionalized carbons were used in the etherification of

79 glycerol by tert-butyl alcohol. Janaun and Ellis [18] obtained a sulfonated carbon catalyst

80 from sugar that showed important activity featuring high thermal resistance. Moreover,

81 Galhardo et al. [19] report on obtaining sulfonated carbon from agro-industrial waste and

82 its subsequent use as acid catalyst in the glycerol etherification with tert-butyl alcohol.

83 Highest conversions were achieved (53\%) at $393 \mathrm{~K}$ using a tert-butyl alcohol: glycerol

84 molar ratio of 4 and $5 \%$ of catalyst. In this case the selectivity towards di- and tri-

85 substituded ethers was $25 \%$ after $4 \mathrm{~h}$ of reaction. Frusteri et al. [7] obtained mono-disperse

86 carbon microspheres via a hydrothermal carbonization process, which were functionalized

87 with acid groups and used in the etherification of glycerol with tert-butyl alcohol. In spite

88 of having a lower acidity than Amberlyst ${ }^{\circledR} 15$, these showed high activity in terms of

89 glycerol conversion and also, they were also stable by retaining the functionalized groups

90 after their use.

91 Among carbons, graphene oxide (GO) and related materials are an emerging new

92 type of very promising carbocatalysts due to their unique properties, including 2D structure, 
93 high stability, and high flexibility for the introduction of catalytic functions [17]. Recently,

94 several authors reported that sulfonated graphene demonstrated excellent activities and

95 selectivities in different acid-catalyzed reactions, including reactions that involve water

96 formation [20-23]. Zhou et al. [24] reported the synthesis of sulfonated graphene by its

97 functionalization through sulfonic acid grafting and its application in the glycerol

98 etherification with isobutene at 333-343 K employing 4 wt\% catalyst and a molar

99 isobutene/glycerol ratio of 4 . Complete glycerol conversion was achieved within $7 \mathrm{~h}$ with

100 high selectivity (92 mol\%) toward the desired poly-substituted ethers.

101 Although this material has been used as an acid catalyst, its particular activity, even

102 in the presence of water, makes it a good candidate to be evaluated in the etherification of

103 glycerol with tert-butyl alcohol. In the present study, we compare three synthesis

104 procedures for the development of sulfonated reduced graphene oxide. We compare the

105 impact the new catalysts to usually employed sulfonated resins and sufonated active carbon

106 on activity, selectivity and stability of the etherification process.

107

\section{2. Experimental section}

109 2.1. Chemicals and catalysts

110 Glycerol (99\%) and tert-butyl alcohol (99.4\%) were obtained from Fisher and Merck 111 respectively. Commercial activated carbon (G60) was obtained from Darco. Amberlyst ${ }^{\circledR} 15$

112 (dry) ion-exchange resin was purchased from Across Organic. Graphite powder $(<20 \mu \mathrm{m}$, 113 synthetic) was obtained from Sigma-Aldrich. The preparation of catalysts based on 114 graphene oxide is described below.

\section{Preparation of graphene oxide}


116 Graphene oxide was synthesized from graphite powder by a modified Hummers method as 117 originally presented by Kovtyukhova, et al. [25,26]. For this purpose, $2.01 \mathrm{~g}$ of graphite 118 powder was mixed with $5.00 \mathrm{~mL}$ of concentrated sulfuric acid, $2.12 \mathrm{~g}$ of potassium 119 persulfate and $2.06 \mathrm{~g}$ of phosphorus pentoxide. This mixture was heated to $353 \mathrm{~K}$ for $2 \mathrm{~h}$. 120 The solid was then filtered using a 0.2 micron Millipore nylon filter and washed first with

$121100 \mathrm{~mL}$ of deionized water, then with $200 \mathrm{~mL}$ of methanol and finally with $200 \mathrm{~mL}$ of 122 ethyl acetate (what we will call washes W-M-EA). The resulting pretreated graphite (PG) 123 was dried at $313 \mathrm{~K}$ for $12 \mathrm{~h}$. Then, $2.16 \mathrm{~g}$ of $\mathrm{PG}$ was mixed with $55 \mathrm{~mL}$ of sulfuric acid at $124273 \mathrm{~K}$ and $7.47 \mathrm{~g}$ of potassium permanganate was then added portionwise. The reaction 125 mixture was stirred at $308 \mathrm{~K}$ for $2 \mathrm{~h}$ and then cooled to $273 \mathrm{~K}$, followed by the addition of 126 an aqueous solution of $7.5 \%$ (v/v) hydrogen peroxide. The solid was centrifuged to 4000 127 rpm during 30 min and the surnatant removed. The resulting solid was washed with W-M128 EA and then was dried at $313 \mathrm{~K}$ for $12 \mathrm{~h}$. This solid was named GO. Figure S1, shows the 129 synthesis scheme.

\section{Reduction of graphene oxide}

131 The reduction of graphene oxide was carried out by three different routes: with i) hydrazine 132 dihydrochloride, ii) ascorbic acid [27] and iii) $\mathrm{Zn} / \mathrm{HCl}$ [28]. For the first route, $1.02 \mathrm{~g}$ of $\mathrm{GO}$ 133 was sonicated in $500 \mathrm{~mL}$ of deionized water for $2 \mathrm{~h}$. Subsequently, $3.02 \mathrm{~g}$ of $\mathrm{Na}_{2} \mathrm{CO}_{3}$ was 134 added to reach a $\mathrm{pH}$ of 9 . Then, $30.04 \mathrm{~g}$ of hydrazine dihydrochloride was added to the 135 suspension and the mixture was refluxed for $24 \mathrm{~h}$. The solution was cooled down to room 136 temperature $(293 \mathrm{~K})$ and filtered through a nylon filter $(0.45 \mathrm{~mm}, 47 \mathrm{~mm})$ and the solid was

137 washed with W-M-EA. The powder was dried at $333 \mathrm{~K}$ for $12 \mathrm{~h}$. The solid obtained by this 138 route was named $(\mathrm{GO}) \mathrm{R}_{\mathrm{H}}$. For the reduction with ascorbic acid, $0.512 \mathrm{~g}$ of $\mathrm{GO}$ was 139 sonicated in $600 \mathrm{~mL}$ of deionized water for $2 \mathrm{~h}$. Then, $164.10 \mathrm{~g}$ of ascorbic acid was added 
at $353 \mathrm{~K}$ under stirring for $2 \mathrm{~h}$. The solution was cooled down to room temperature $(293 \mathrm{~K})$

141 and filtered through a nylon filter and washed with W-M-EA. The powder was dried at 333

$142 \mathrm{~K}$ for $12 \mathrm{~h}$. The solid obtained was named $(\mathrm{GO}) \mathrm{R}_{\mathrm{A}}$. Finally, for the reduction with $\mathrm{Zn} / \mathrm{HCl}$,

$1430.503 \mathrm{~g}$ of $\mathrm{GO}$ was sonicated in $500 \mathrm{~mL}$ of deionized water for $2 \mathrm{~h}$ and acidified $(\mathrm{pH}=1.9)$

144 with concentrated $\mathrm{HCl}$. Then, $1.00 \mathrm{~g}$ of zinc powder was added at room temperature (298

$145 \mathrm{~K}$ ) under stirring for $10 \mathrm{~min}$, follow by the addition of $125 \mathrm{~mL}$ of concentrated $\mathrm{HCl}$. After 1

$146 \mathrm{~h}$, the solid was filtered through a nylon filter and washed with $1.5 \mathrm{~L}$ of deionized water.

147 The black powder was dried at $333 \mathrm{~K}$ for $12 \mathrm{~h}$. The obtained solid was named (GO) $\mathrm{R}_{\mathrm{Z}}$.

148 Figure S2, shows the synthesis scheme.

149 Sulfonation of reduced graphene oxide

150 Graphene oxide $(\mathrm{GO})$ as well the reduced graphene oxides $(\mathrm{GO}) \mathrm{R}_{\mathrm{H}},(\mathrm{GO}) \mathrm{R}_{\mathrm{A}}$, and $(\mathrm{GO}) \mathrm{R}_{\mathrm{Z}}$, 151 were sulfonated through treatment with 4-benzenediazoniumsulfonate which was in situ 152 generated. For this purpose, $0.273 \mathrm{~g}$ of the initial solid was sonicated in $40 \mathrm{~mL}$ of deionized 153 water for $2 \mathrm{~h}$. Then, $0.947 \mathrm{~g}$ of sodium nitrite and $0.795 \mathrm{~g}$ of sulfanilic acid were added to 154 the resulting solution, allowing the in situ formation of the diazonium salt, and the reaction 155 was conducted at $298 \mathrm{~K}$ for $24 \mathrm{~h}$. The solution was filtered through a nylon filter and 156 washed with $150 \mathrm{~mL}$ of $1 \mathrm{M} \mathrm{HCl}$ and $250 \mathrm{~mL}$ of acetone. The powder obtained was dried at

$157313 \mathrm{~K}$ at $333 \mathrm{~K}$ for $12 \mathrm{~h}$. The resulting samples were named (GO)-S, (GO) $\mathrm{R}_{\mathrm{H}^{-}} \mathrm{S},(\mathrm{GO}) \mathrm{R}_{\mathrm{A}^{-}} \mathrm{S}$, 158 and $(\mathrm{GO}) \mathrm{R}_{\mathrm{Z}} \mathrm{S}$. Figure $\mathbf{S 3}$, shows the synthesis scheme.

159 In order of comparison, activated carbon (G60) was similarly sulfonated to graphene oxide 160 (AC)-S, reduced with hydrazine dihydrochloride $(A C) R_{H}$ and, finally, the reduced solid 161 was sulfonated to obtain $(\mathrm{AC}) \mathrm{R}_{\mathrm{H}^{-}} \mathrm{S}$. 


\section{Textural properties}

165 Surface area measurements were conducted through applying the BET equation to nitrogen 166 physisorption isotherms at $77 \mathrm{~K}$ measured in a TriStar II plus. The samples were outgassed 167 at 3 mTorr and $423 \mathrm{~K}$ for $12 \mathrm{~h}$ prior to analysis. Characterization by transmission electron 168 microscopy (TEM) was carried on a JEOL JEM-2011TEM. To prepare samples for TEM, 169 graphene derived samples were dispersed in ethanol, and deposited onto copper grids. 170 Scanning electron microscopy (SEM) images were obtained on a JEOL JSM-790CF 171 microscope. X-ray powder diffraction (XRD) patterns were recorded at room temperature 172 on Empyrean X-ray diffractometer (Malvern Panalytical Ltd., Royston, UK) operating with $173 \mathrm{Cu} \mathrm{K \alpha}$ radiation $(\lambda=0.15418 \mathrm{~nm})$ with a scan speed of $1^{\circ} \min ^{-1}$ and a scan range of 5-65 174 at $30 \mathrm{kV}$ and $15 \mathrm{~mA}$. Raman spectroscopy was performed using a Raman HORIBA JOBIN 175 YVON Labram HR800UV confocal microscope equipped with a Peltier cooled CCD 176 detector. The exciter wavelength is $532 \mathrm{~nm}$. The laser power delivered to the sample was $1770.02 \mathrm{~mW}$ (use of an optical density filter). The device was equipped with an Olympus 178 confocal microscope that allows working backscatter. A diffraction grating with 600 179 lines.mm $\mathrm{mm}^{-1}$ was used and the opening of the confocal hole is $200 \mu \mathrm{m}$. The spectral 180 resolution was $1.5 \mathrm{~cm}^{-1}$. The spectrometer was calibrated with a silicon sample. The 181 LabSpec 5 software allows the acquisition and processing of results.

\section{Chemical composition}

184 The contents of carbon, hydrogen, oxygen and sulfur in graphene-based catalysts were 185 obtained with an elemental analyzer NA2100 Protein, Thermoquest Instruments.-XPS was 186 performed in a high vacuum chamber (pressure $\leq 9 \times 10^{-8} \mathrm{~Pa}$ ) on a Kratos Axis Ultra DLD 187 spectrometer equipped with a monochromatic radiation source $\mathrm{Al}$ Mono $\left(\mathrm{Al}_{\mathrm{k} \alpha}: 1486.6 \mathrm{eV}\right)$ 
operating at $150 \mathrm{~W}(15 \mathrm{kV}$ and $10 \mathrm{~mA})$. Survey spectra were recorded with a step of $1 \mathrm{eV}$ 189 (transition energy: $160 \mathrm{eV}$ ). Based on the collected basic information, high-resolution XPS spectra were collected at a step of $0.1 \mathrm{eV}$ (transition energy: $20 \mathrm{eV}$ ).

\section{Acid properties}

193 The acidity of GO samples and activated carbon was confirmed by Boehm titration. $0.1 \mathrm{~g}$ 194 of catalyst was added to $20 \mathrm{~mL}$ of $2 \mathrm{M} \mathrm{NaCl}$ solution. After $24 \mathrm{~h}$ of stirring at room 195 temperature, the solution was titrated with $0.1 \mathrm{M} \mathrm{NaOH}$ solution. The number of acid sites 196 was then calculated from the amount of $\mathrm{NaOH}$ required in the titration. This method has 197 been commonly used in previous studies, correlating the loading of $\mathrm{SO}_{3} \mathrm{H}$ calculated by 198 elemental analysis [29-31]. For the Amberlyst ${ }^{\circledR}$ 15, Fourier transform Infrared spectra (FT199 IR) of pyridine adsorbed was used on a Nicolet Magna 550-FT-IR spectrometer with a 2 $200 \mathrm{~cm}^{-1}$ optical resolution. The sample were first pressed into self-supporting wafers (diameter: $2011.6 \mathrm{~cm}$ ) and pretreated from room temperature to $403 \mathrm{~K}$ in an IR cell connected to a

202 vacuum line. Pyridine adsorption was carried out at $403 \mathrm{~K}$. After establishing a pressure of $203133 \mathrm{~Pa}$ at equilibrium, the cell is evacuated at $423 \mathrm{~K}$ to remove all physisorbed species. The 204 amount of pyridine adsorbed on the Brønsted and Lewis sites is determined by integrating 205 the band areas at respectively $1545 \mathrm{~cm}^{-1}$ and $1454 \mathrm{~cm}^{-1}$. Lewis acidity not was detected for 206 this resin.

\subsection{Etherification of glycerol with tert-butyl alcohol and analysis}

210 with temperature control, a manometer and stirring control. In order to avoid diffusion 211 limitations, in all experiments the stirring speed was adjusted to $1200 \mathrm{rpm}$. In previous 
212 studies [10, 32], it was determined that at high rates of agitation, the selectivity towards

213 ethers is higher, while at speeds below $1000 \mathrm{rpm}$, oligomerization of isobutene can occur.

214 For the etherification reaction of glycerol with tert-butyl alcohol, $2.79 \mathrm{~g}$ of glycerol, $9.00 \mathrm{~g}$

215 of tert-butyl alcohol (glycerol/tert-butyl alcohol molar ratio of 0.25 ) and a constant catalyst

216 loading of $7.5 \%$ (with respect to the glycerol mass) was used in all experiments. The

217 reaction temperature was set at $363 \mathrm{~K}$ and the samples were taken at different times for 10

$218 \mathrm{~h}$ under autogenous pressure, which is the pressure reached inside the reactor by the same

219 reaction system, without establishing a pressure due to an external atmosphere. The

220 pressures reached up to 5 bar. The evolution of the reaction was followed by gas

221 chromatography using a chromatograph model Agilent HP-6890, DB-WAX column and a

222 FID detector and butanol (99\%, Sigma Aldrich) as internal standard. The temperature

223 program used consisted of an isotherm at $313 \mathrm{~K}$ for 2 minutes, an increase rate of 293

$224 \mathrm{~K} / \mathrm{min}$ until reaching $513 \mathrm{~K}$, where there was another isotherm for 5 minutes. Glycerol,

225 MTBG (3-tert-butoxy-1,2 propanediol and 2-tert-butoxy-1,3 propanediol) and DTBG (2,3-

226 di-tert-butoxy-1-propanol and 1,3-di-tert-butoxy-2-propanol) response factors were

227 determined by calibration performed with standards. MTBG and DTBG (which is not

228 commercially available), were isolated from the products of the etherification reaction by

229 column chromatography (1:9 ethyl acetate/petroleum ether) and identified by ${ }^{1} \mathrm{H}$ NMR.

230 Glycerol conversion (\%), product selectivity (\%) and the molar yield (\%), were calculated

231 using the following equations [16]:

232

$$
\text { Glycerol conversion }(\%)=\frac{\text { moles of reacted glycerol }}{\text { moles of initial glycerol }}
$$

233

$$
\text { Product selectivity }(\%)=\frac{\text { moles of obtained product }}{\text { total moles of product }}
$$




$$
\text { Molar yield }(\%)=\frac{\text { moles of obtained product }}{\text { moles of initial glycerol }}
$$

235 The carbon balance with respect to glycerol was close to $97 \%$ for all the catalysts.

\section{3. Results and discussion}

\section{3.1. Textural properties}

239 Table 1 reports the BET Surface, the elemental analysis and the acidity achieved from

240 Boehm titration of activated carbons, Amberlyst ${ }^{\circledR} 15$ (reference catalyst) and graphene

241 oxides. The BET surface area obtained for activated carbon shows that a reduction process

242 leads to a small decrease in the initial value (from 978 to $919 \mathrm{~m}^{2} \mathrm{~g}^{-1}$ ), while the sulfonation

243 process drastically decreases the surface area $\left(224 \mathrm{~m}^{2} \mathrm{~g}^{-1}\right)$, probably because of the

244 obstruction of some pores [33]. Amberlyst ${ }^{\circledR} 15$ features a BET area of $53 \mathrm{~m}^{2} \mathrm{~g}^{-1}$, which is

245 characteristic of this resin with pores in the macroporous range comprised between of 40 to

$24680 \mathrm{~nm}$ [34]. Differently, graphene oxide (GO) exhibits low surface areas $\left(5 \mathrm{~m}^{2} \mathrm{~g}^{-1}\right)$. The

247 theoretical value for completely exfoliated and isolated graphene sheets is $2600-2700 \mathrm{~m}^{2} \mathrm{~g}^{-}$

248 1. Yet, the textural properties of GO in the wet/dispersed state differ significantly from 249 those in the dried state [17], as the restacking of the sheets upon drying leads to a strong 250 decrease in the adsorption capacity [35].

251 The reduction process using hydrazine dihydrochloride leads to a small increase in surface

252 area by removing some oxygenated groups from the surface (from 5 to $22 \mathrm{~m}^{2} \mathrm{~g}^{-1}$ ), while 253 sulfonation leads to BET areas of less than $11 \mathrm{~m}^{2} \mathrm{~g}^{-1}$ for sulfonated reduced GO solid.

255 The XRD patterns of graphite, pre-oxidized graphite, $\mathrm{GO},(\mathrm{GO}) \mathrm{R}_{\mathrm{A}},(\mathrm{GO}) \mathrm{R}_{\mathrm{H}}$, and $(\mathrm{GO}) \mathrm{R}_{\mathrm{Z}} \mathrm{S}$ 256 are shown in Figure 1. According to XRD for the pre-oxidized graphite, it shows no 
257 structural changes after treatment with the mixture between concentrated sulfuric acid, 258 potassium persulfate and phosphorus pentoxide, retaining the same very strong [002] peak 259 at $26.57^{\circ}$ as the starting graphite, although XPS (see XPS analysis below) allows to reveal 260 the presence of some oxygenated groups in the surface of this material. For the GO sample 261 a peak at $10.13^{\circ}$ is observed which is due to the formation of hydroxyl, epoxy and carboxyl 262 groups ([001] plane). The introduced oxygenated functions increase the interlayer spacing 263 from $0.34 \mathrm{~nm}$ in graphite to $0.87 \mathrm{~nm}$ in $\mathrm{GO}$, and the stacking height and the layered 264 arrangement was $41 \mathrm{~nm}$ with 110 sheets and $10 \mathrm{~nm}$ with 12 sheets respectively. After 265 reduction of the $\mathrm{GO}$ with ascorbic acid $\left((\mathrm{GO}) \mathrm{R}_{\mathrm{A}}\right)$, the oxygen- containing functional groups 266 are removed, which lead to shift of the GO peak to $24.33^{\circ}$ and a weak [100] band at $43.4^{\circ}$. 267 This feature can be related to the degradation of the layered structure during the exfoliation 268 step and suggests an intermediate crystalline structure between graphite and amorphous 269 carbon that has been named turbostratic structure or random layer lattice structure [29,36]. 270 For this same solid, the interlayer spacing is $0.37 \mathrm{~nm}$ and the layered arrangement was 1.13

$271 \mathrm{~nm}$ with 3 sheets. The reduction process using hydrazine dihydrochloride $\left((\mathrm{GO}) \mathrm{R}_{\mathrm{H}}\right)$ not all 272 oxygen groups are eliminated (XPS analysis below), for this reason besides the main peak 273 at $26.18^{\circ}$, a peak at $13.16^{\circ}$ is observed, which suggests that part of the initial structure of $274 \mathrm{GO}$ is maintained after the reduction process with this agent. The interlayer spacing is 0.34 $275 \mathrm{~nm}$ for graphene oxide reduced by this route and $0.67 \mathrm{~nm}$ for the remaining non-reduced 276 graphene oxide. On the other hand, the sulfonation process does not affect the structure of 277 the reduced oxide with $\mathrm{Zn} / \mathrm{HCl}\left((\mathrm{GO}) \mathrm{R}_{\mathrm{Z}}-\mathrm{S}\right)$ where a [002] peak at $25.25^{\circ}$ is predominant. 278 Additionally, it a broad shoulder at $22.23^{\circ}$ can be inferred, presumably induced by a 279 bimodal or multimodal character of the interlayer spacing of $(\mathrm{GO}) \mathrm{R}_{\mathrm{Z}} \mathrm{S}$ powder [37]. The 280 stacking height and the layered arrangement for this sample was $1.41 \mathrm{~nm}$ with 4 sheets, 
281 respectively. This result confirms the successful exfoliation through the reduction process

282 and with the respective functionalization approaches.

283

284 The Raman spectra of graphite, $\mathrm{GO},(\mathrm{GO}) \mathrm{R}_{\mathrm{H}}$ and $(\mathrm{GO}) \mathrm{R}_{\mathrm{A}}$ are shown in the Figure 2. These 285 confirm the observations by the XRD patterns i.e., structural modification during the 286 oxidation process from graphite to graphene oxide. The Raman spectrum of graphite 287 displays a strong peak at $1580 \mathrm{~cm}^{-1}$, corresponding to the G-band, which is attributed to the 288 first order scattering of the $\mathrm{E}_{2 \mathrm{~g}}$ phonon of the $\mathrm{sp}^{2}$ carbon-carbon bond [38]. The Raman 289 spectra of GO, shows a slight shift of the G-band to $1584 \mathrm{~cm}^{-1}$. For $(\mathrm{GO}) \mathrm{R}_{\mathrm{H}}$ and $(\mathrm{GO}) \mathrm{R}_{\mathrm{A}}$, 290 the G-band is further shifted to values of $1590 \mathrm{~cm}^{-1}$. The shift of this band could be related 291 to the number of layers present in the material [39]. After oxidation process of the graphite 292 to GO, the D-band develops, which represents the defect sites associated with vacancies 293 and grain boundaries [26, 29] due to extensive oxidation [40]. This D-band (around 1355 $294 \mathrm{~cm}^{-1}$ ) is due to a breathing mode of $\mathrm{A}_{1 \mathrm{~g}}$ symmetry involving phonons near the $\mathrm{K}$ zone 295 boundary [41].

297 The morphological characteristics of the samples were investigated by microscopy. The 298 achieved scanning electron microscopy (SEM) images show that the laminar form of the 299 graphite was not significantly altered by the oxidation processes. The observed corrugation 300 of GO sheets can be attributed to the breaking of the planar polyaromatic structure [26], 301 (Fig. 3b). After the reduction process (with ascorbic acid), the restoration of the sheets by 302 pi-interactions is evident, while ultrasound treatment, during the preparation of $(\mathrm{GO}) \mathrm{R}_{\mathrm{A}}$, 303 leads to irreversible separation of the layers and a completely corrugated morphology is 304 observed (Fig. 3d). 
305 The results obtained from SEM convey well with those achieved by transmission electron 306 microscopy (TEM) (Fig. 4). The TEM image of graphite presents electron dark areas that 307 indicate the existence of several layers of the polyaromatic structure. Electron clear regions 308 present in GO, indicate much thinner films of few layers of graphene oxide. Additionally, 309 GO sample present sizes of 200 to $500 \mathrm{~nm}$. The reduction with ascorbic acid and 310 subsequent sulfonation does not alter the morphology. Yet, the reduction with hydrazine

311 allows to observe large agglomerations, probably due to the combination of the reduced 312 layers with the remaining graphene oxide which was not reduced (determined by XRD).

314 The quantitative energy dispersive X-ray spectroscopy (EDS) mapping of (GO) $\mathrm{R}_{\mathrm{H}^{-}} \mathrm{S}$ and $315(\mathrm{GO}) \mathrm{R}_{\mathrm{A}}-\mathrm{S}$, reveals a homogeneous distribution of $-\mathrm{PhSO}_{3} \mathrm{H}$ functionalities, which indicates 316 that these are not exclusively located at the edges [20], (Figure 4). For the functionalization 317 of $(\mathrm{GO}) \mathrm{R}_{\mathrm{z}}$ with the aryl diazonium salt of the sulfanilic acid, a re-hybridization of the $\mathrm{C}$ 318 atoms from $\mathrm{sp}^{2}$ to $\mathrm{sp}^{3}$ is required, to form covalent bonds. It is well known that the chemical 319 reduction of graphene oxide generates a substantial amount of defects, including holes in 320 the basal plane, which are allow to increased the amount of grafted $-\mathrm{PhSO}_{3} \mathrm{H}$ groups [42].

\section{Elemental analysis}

323 Elemental analysis by combustion was used to investigate the degree of reduction of the

324 powder samples and the degree of sulfonation. Table 1 summarizes the results of the 325 elemental analysis, in addition to the determination of the $\mathrm{C} / \mathrm{O}$ and $\mathrm{S} / \mathrm{C}$ ratios. The obtained 326 graphene oxide $(\mathrm{GO})$ has a $\mathrm{C} / \mathrm{O}$ ratio of 0.78 , which reflects high oxidation in the material 327 with respect to the starting graphite, which features a $\mathrm{C} / \mathrm{O}$ ratio of 56.64. Through reduction 328 a notable differences in the $\mathrm{C} / \mathrm{O}$ ratios can be observed. According to our results, the 
reduction with $\mathrm{Zn} / \mathrm{HCl}$ is more effective than with hydrazine hydrochloride and ascorbic 330 acid, generating a $\mathrm{C} / \mathrm{O}$ ratio of 18.1 against 2.82 and 3.43 for $(\mathrm{GO}) \mathrm{R}_{\mathrm{H}}$ and $(\mathrm{GO}) \mathrm{R}_{\mathrm{Z}}$, 331 respectively. With respect to the $\mathrm{S} / \mathrm{C}$ ratio, it is possible to observe that the graphene oxide 332 contains residual sulfur, which is due to the oxidizing process in which sulfuric acid was 333 used $[43,44]$. It has been described that this residual sulfur is present as sulphate species 334 [45] and is lodged within the leaves of GO [42]. These sulphate species is removed during 335 the reduction process, probably due to the restoration of the leaves and the high solubility in 336 water of the sulphate group [46]. Hence, the presence of sulfur in $(\mathrm{GO}) \mathrm{R}_{\mathrm{H}},(\mathrm{GO}) \mathrm{R}_{\mathrm{Z}}$ and $337(\mathrm{GO}) \mathrm{R}_{\mathrm{A}}$ is exclusively due to the functionalization with sulphanilic acid. The S/C ratio in 338 these solids is greatest in $(\mathrm{GO}) \mathrm{R}_{\mathrm{A}}-\mathrm{S}$, followed by $(\mathrm{GO}) \mathrm{R}_{\mathrm{Z}}-\mathrm{S}$ and $(\mathrm{GO}) \mathrm{R}_{\mathrm{H}^{-}} \mathrm{S}$. These results 339 thus indicate that the employed GO reduction strategy significantly influences the degree of 340 S-functionalization. Probably the poor agglomeration of the sheets after the reduction with 341 L-ascorbic acid (TEM analysis), promotes the grafting of $-\mathrm{PhSO}_{3} \mathrm{H}$ groups on the surface.

343 The XPS spectrum of the C1s for graphite, shows a predominant peak at $284.4 \mathrm{eV}$ 344 corresponding to $\mathrm{sp}^{2}$ carbon and a small peak at $286.4 \mathrm{eV}$ corresponding to a very low 345 amount of alcoholic or phenolic C-O-H groups [47] present in the starting material (Fig. 346 5a). The pre-oxidation treatment of graphite with $\mathrm{K}_{2} \mathrm{~S}_{2} \mathrm{O}_{8} / \mathrm{P}_{2} \mathrm{O}_{5}$ (Fig. 5b) generated a low 347 number of $\mathrm{C}-\mathrm{O}$ and $\mathrm{C}=\mathrm{O}$ groups characterized by the low intensity peaks at 286.4 and $348287.7 \mathrm{eV}$, respectively, while the $\mathrm{Csp}^{2}$ peak at $284.4 \mathrm{eV}$ remains intense. In GO the 349 presence of a high content $\mathrm{Csp}^{3}$ carbons was determined (284.2 $\left.\mathrm{eV}\right)$, as well as the 350 functional groups C-O-C (286.2 eV), C=O (288.2 eV) and $\mathrm{O}-\mathrm{C}=\mathrm{O}(289.5 \mathrm{eV})$, which 351 confirm the oxidation process (Fig. 5c). The reduction of GO by the use of hydrazine 352 dihydrochloride partially restored the aromatic structure of the material, although some 
353 oxygenated groups remain observable, principally C-O-C (286.6 eV), (Figure 5d). During

354 the reduction, parts of the basal planes near the edges are reduced and subsequently snap

355 together due to $\pi-\pi$ interactions, thus narrowing the interlayer distance. Consequently, the

356 reducing agent, hydrazine dihydrochloride, is hindered to penetrate further into the interior

357 of the GO particles, presumably leading to the lower degree of reduction [37] and greater

358 agglomeration (TEM images). The reduction of the GO by ascorbic acid, leads to a greater

359 restoration of the aromatic structure compared with the hydrazine dihydrochloride, since

360 the amount of oxygenated groups after the process was much lower (high $\mathrm{C} / \mathrm{O}$ ratio),

361 (Table 1). According to Guo et al., L-ascorbic acid significantly reduces the amount of

362 epoxy and hydroxylic groups, which are the most abundant groups in the GO. In addition, a

363 high concentration of L-ascorbic acid, as in our case, can generate oxalic acid and guluronic

364 acids (generated from the decomposition of dehydroascorbic acid) that are able to form

365 hydrogen bonds with residual oxygen groups and prevent $\pi-\pi$ interactions of the graphene

366 sheets, which hinders agglomeration [27], (TEM images). The XPS spectrum of (GO) $\mathrm{R}_{\mathrm{Z}^{-}} \mathrm{S}$

367 (Figure 5f), show the presence of a negligible amount of oxygenated groups that have been

368 conserved after the functionalization process on $(\mathrm{GO}) \mathrm{R}_{\mathrm{z}}$. Figure $\mathbf{6}$, shows the determination

369 of the atomic concentration (\%) determined by XPS, where it is possible to corroborate the

370 different oxygenated groups present in the graphene oxide, after the reduction and

371 sulfonation compared to the starting material.

372

373 Acidity

374 The acidity measurements of the samples were correlated with the number of sulfonic

375 groups (sulfur content) present in the surface and corroborated by the Boehm titration

376 (Table 1). This approach has been used in other studies that find concordance between the 
377 results for sulfonated reduced graphene oxide [26,48]. For the activated carbon (AC), the

378 total acidity comprises the sulfonic groups and the original oxygenated groups present in

379 this type of material. According to Cordoba et al. [49] activated carbon G60 presents

380 carboxylic acids, anhydrides and lactone groups, which are responsible for its surface

381 acidity $\left(0.71 \mathrm{mmol}\left[\mathrm{H}^{+}\right] \mathrm{g}^{-1}\right)$. After the sulfonation process of AC the total acidity increases

382 to $1.76 \mathrm{mmol}\left[\mathrm{H}^{+}\right] \mathrm{g}^{-1}$; of which $1.05 \mathrm{mmol}\left[\mathrm{H}^{+}\right] \mathrm{g}^{-1}$ correspond to the sulfonated grafted

383 groups. The acidity of the GO, in both cases, was influenced by the presence of sulfate

384 groups remaining from the graphite oxidation processes: GO exhibited a total acidity of

$3850.51 \mathrm{mmol}\left[\mathrm{H}^{+}\right] \mathrm{g}^{-1}$, of which $0.45 \mathrm{mmol}\left[\mathrm{H}^{+}\right] \mathrm{g}^{-1}$ corresponded to the sulfonated groups,

386 which belong to the groups resulting from the functionalization. After the reduction of GO,

387 the disappearance of the remaining sulfate was evidenced (see atop) and the acidity

388 determined by the Boehm titration equals almost to zero, which is due to the few acidic

389 oxygenated groups remaining on the surface of the reduced graphene oxide. Finally, the

390 acidity obtained by titration of Boehm for the sulfonated reduced graphene oxides was

391 similar to the acidity obtained by the correlation of the sulfur present in these catalysts.

393 3.2. Etherification of glycerol with tert-butyl alcohol

394 According to our previous work [16], we determined the thermodynamics of the 395 etherification of glycerol with tert-butyl alcohol by the use of discontinuous reactors at 363

$396 \mathrm{~K}$ under autogenous pressure. The etherification of glycerol and tert-butyl alcohol is a 397 reaction limited by a thermodynamic equilibrium. In our experimental conditions the 398 maximum glycerol conversion expected is $80 \%$. 
401 To determine the partial order of the reaction between glycerol (Gly) and tert-butyl alcohol 402 (TBA), the variation of the initial reaction rate and the concentration of the reactants were 403 studied. For this, the catalysts (AC)-S and $(\mathrm{GO}) \mathrm{R}_{\mathrm{A}}-\mathrm{S}$ were used at $363 \mathrm{~K}$ and were 404 calculated by the natural logarithm of the rate equation [16]. The initial rate were measured 405 in a series of experiments at different initial concentration of glycerol ranged from $2.0 \times 10^{-4}$ 406 to $1.0 \times 10^{-3} \mathrm{~mol} \mathrm{~cm}^{-3}$ with a molar ratio tert-butyl alcohol/glycerol from 10 to 40 . In these 407 conditions, the concentration of the exceeding reactant can be considered as almost 408 invariant. The slope of the linear regression in Fig. 7 of the $\ln r_{0}$ plot as a function of $409 \ln [\mathrm{Gly}]_{0}$ corresponds to the partial order with respect to Gly. Additionally, experiments 410 were carried out where the concentration of Gly was maintained constant and the TBA 411 concentration was varied from $4.0 \times 10^{-4}$ to $2.0 \times 10^{-3} \mathrm{~mol} \mathrm{~cm}^{-3}$. The partial kinetic orders for 412 (AC)-S with respect to glycerol was 0.16, while the order for TBA was 0.84. For the 413 catalyst $(\mathrm{GO}) \mathrm{R}_{\mathrm{A}}-\mathrm{S}$, the order obtained with respect to glycerol was 0.42 , while for the TBA 414 1.60. These results agree with those obtained by Frusteri et al., [50] who evaluated the 415 partial orders of the solid-acid resin Amberlyst ${ }^{\circledR} 15$ in the glycerol etherification which 416 were found to be of 0.3 with respect to Gly and an order of 1.7 with respect to tert-butyl 417 alcohol, suggesting that the etherification reaction occurs through fast protonation of TBA 418 on the acid sites forming a tertiary carbocation able to react with glycerol strongly adsorbed 419 on the catalyst surface.

420 These results further confirm the Langmuir-Hinshelwood (LH) as most suitable kinetic 421 model as indicated by Kiatkittipong et al. [51]. The apparent activation energy of the 422 Amberlyst $^{\circledR} 15$ was $63 \mathrm{~kJ} \mathrm{~mol}^{-1}$, which is very close to the values calculated in other kinetic 423 studies for this catalyst [52]. 
In figure 8, the glycerol conversion was compared as a function of the reaction time

427 for following catalysts: (AC)-S, (AC) $\mathrm{R}_{\mathrm{H}^{-}} \mathrm{S}$ and Amberlyst ${ }^{\circledR} 15$ (reference catalyst [14, 51]), 428 (GO), (GO)-S, (GO) $\mathrm{R}_{\mathrm{H}^{-}} \mathrm{S},(\mathrm{GO}) \mathrm{R}_{\mathrm{Z}^{-}} \mathrm{S},(\mathrm{GO}) \mathrm{R}_{\mathrm{A}}-\mathrm{S}$. By employing A-15 conversion increases 429 rapidly and reaches a plateau at $64 \%$ within $1 \mathrm{~h}$. The plateau is $16 \%$ lower than the 430 predicted equilibrium value (80\%), which indicates that conversion is hampered by 431 deactivation of the sulfonic resin, probably due to a product inhibition effect, e.g. by $\mathrm{H}_{2} \mathrm{O}$ 432 [16]. As expected, graphite and AC as catalysts do not allow to observe glycerol conversion 433 (Table 2). Although these solids feature oxygenated groups (graphite and AC) the acidity 434 that these groups confer is to weak to promote etherification. Sulfonated AC, permits to 435 reach a glycerol conversion of 35\%, which suggests that the presence of sulfonated groups 436 promotes the reaction. Additionally, GO was tested as catalyst. As evidences through XPS 437 GO contains oxygenated groups on the surface, as determined by the Boehm titration 438 (Table 1), which acidity is low to promote etherification. Additionally GO contained a 439 substantial amount of sulphate species from the preparation process, which could confer the 440 appropriate acid strength to carry out the reaction. Indeed, one strategy to functionalize 441 graphene with acid groups is its direct immersion in concentrated sulfuric acid [53]. The 442 glycerol conversion achieved with GO amounts to $19 \%$.

445 further compared in terms of initial activity $\left(\mathrm{A}_{0}\right)$, where possible deactivation does not 446 occur. $\mathrm{A}_{0}$ was obtained from the slope of the tangent at zero time fitted to the conversion 447 vs. time graphs (Figure 8). The initial activity of the catalyst based on sulfonated reduced 448 graphene oxide is very close to the activity of the sulfonic resin A-15, (Table 2), which can 
449 be related to the fact that both the Amberlyst ${ }^{\circledR} 15$ and the graphene-based solids contain the 450 same acidic surface moieties (i.e. $-\mathrm{PhSO}_{3} \mathrm{H}$ ). Additionally, both types of materials present 451 the absence of micropores as in the case of activated carbons, where substantially lower 452 initial activities are observed. The initial activity $\left(\mathrm{A}_{0}\right)$ of the catalysts evaluated was related 453 to the acidity obtained for each catalyst (Figure 9). It can be seen that, in general, there is a 454 correlation for catalysts based on graphene oxide, where the initial activity depends on the 455 concentration of acid. For catalysts based on activated carbon, the activity does not increase 456 with increasing acid concentration.

457 The recyclability of (AC)-S and $(\mathrm{GO}) \mathrm{R}_{\mathrm{A}}-\mathrm{S}$ was investigated through comparing the 458 molar yields toward MTBG and DTBG. After 3 recycling cycles the glycerol conversion 459 using $(\mathrm{GO}) \mathrm{R}_{\mathrm{A}}-\mathrm{S}$, decreases by $11 \%$ and the molar yield towards poly-substituted ethers 460 decreases of than 50\% (from 22 to 10\%), Fig. 10. As similar result is observed for (AC)-S, 461 although in this case the conversion decreases only by $1 \%$. In the case the catalysts are 462 regenerated through ethanol washing using Soxhlet, the initial conversion can be recovered 463 for all catalysts. This suggests the deactivation occurs through adsorption of reagents and 464 products on the active sites. This was evidenced through analyzing the ethanol fraction 465 from the washing cycle by gas chromatography. Here the main peaks are glycerol and 466 MTBG. Hence, it is possible to recover the initial activity by means of solvent washing. 467 Elemental analysis was used to verify the elemental ratio in the sulfonated reduced 468 graphene oxide catalysts after use. The results showed that the proportions of carbon, 469 oxygen and sulfur elements do not have noticeable changes. These observations indicate 470 that sulfonated reduced graphene oxide is a stable and easily recyclable catalyst for 471 etherification with glycerol. 
474 The etherification of glycerol with tert-butyl alcohol is a reaction of successive routes that 475 produces water as a by-product and five different alkyl ethers, which are: MTBG (3- tert476 butoxy-1,2 propanediol and 2-tert-butoxy-1,3 propanediol), DTBG (2,3-di-tert-butoxy-1477 propanol and 1,3-di-tert-butoxy-2- propanol) and TTBG (tri-tert-butoxy-propane). Side 478 reactions can occur such as the dehydration of tert-butyl alcohol to isobutylene (IB) 479 followed of its dimerization. Under the performed reaction conditions, no diisobutylene 480 was detected as the isobutylene yield estimated from the autogenous pressure is negligible $481(<1 \%)$ [16]. Fig. 11 compares MTBG (primary product) and the poly-substituted ethers 482 (DTBG and TTBG) molar yields as function of the overall glycerol conversion employing 483 Amberlyst $^{\circledR}$ 15, and sulfonated reduced graphene oxide-based catalyst. Table 2 reports 484 conversion and product selectivity obtained after $10 \mathrm{~h}$ of reaction.

485 Using A-15, the yield of the primary product (MTBG) reaches a maximum at ca. 60\% 486 glycerol conversion. The DTBG (secondary product) is starting to be formed at $23 \%$ 487 glycerol conversion (extrapolated value at zero conversion). After $10 \mathrm{~h}$ of reaction, one 488 quarter of the products are composed of DTBG, whereas the yield of TTBG (ternary 489 product) is negligible $(0.3 \%)$. For the catalyst (AC)-S, the formation of DTBG occurs at 490 low conversion $(\sim 20 \%)$. This is related to the high microporosity of activated carbon in 491 which the reaction in sterically limited spaces can have a major impact on selectivity. In a 492 previous study we have indeed observed that molecular shape selectivity and confinement 493 effect in zeolites have a major effect on product selectivity in the glycerol etherification $494[16]$.

495 For catalysts based on sulfonated reduced graphene oxide, the selectivity obtained towards 496 DTBG depends on the synthesis strategy. Catalysts obtained through hydrazine 
497 dihydrochloride and ascorbic acid ((GO) $\mathrm{R}_{\mathrm{H}^{-}} \mathrm{S}$ and $\left.(\mathrm{GO}) \mathrm{R}_{\mathrm{A}}-\mathrm{S}\right)$ allow to achieve selectivities 498 toward DTBG of 29 and 27\%, respectively, after $10 \mathrm{~h}$ of reaction (Table 2). In fact, these 499 solids do not present any porosity and, therefore, the formation of DTBG is observed only 500 after a glycerol conversion of 24\%. (Fig. 11). Although the conversion after $10 \mathrm{~h}$ of 501 reaction is similar for the three catalysts $\left((\mathrm{GO}) \mathrm{R}_{\mathrm{H}^{-}} \mathrm{S}\right.$, $(\mathrm{GO}) \mathrm{R}_{\mathrm{Z}^{-}} \mathrm{S}$ and $\left.(\mathrm{GO}) \mathrm{R}_{\mathrm{A}^{-}} \mathrm{S}\right)$, the 502 selectivity obtained with $(\mathrm{GO}) \mathrm{R}_{\mathrm{Z}^{-}} \mathrm{S}$ differs significantly and reaches merely $12 \%$ DTBG 503 (Table 2). Further, for the catalyst $(\mathrm{GO}) \mathrm{R}_{\mathrm{Z}}-\mathrm{S}$, it is observed that DTBGs are formed upon 504 reaching a glycerol conversion of 54\%. These large differences in selectivity are related to 505 the amount of oxygen groups in these catalysts, which influence the 506 hydrophobic/hydrophilic $(\mathrm{H} / \mathrm{H})$ balance. According to Huang et al., the hydrophobicity of 507 graphene oxide increases with the degree of reduction or elimination of oxygenated groups 508 [54]. On the other hand, Mitra and Azizighannad evaluated the hydrophobicity index of the 509 graphene oxides reduced with $\mathrm{Zn} / \mathrm{HCl}$, where using different amounts of $\mathrm{Zn}$, they obtained 510 graphene oxide with different percentages of oxygen. The results of their study also 511 corroborate that a lower oxygen content leads to a higher hydrophobicity index [55]. 512 Indeed, the $\mathrm{H} / \mathrm{H}$ balance on selectivity has previously been discussed for zeolites for the 513 glycerol etherification with tert-butyl alcohol $[16,56,57]$. According to the results of this 514 study, the $\mathrm{H} / \mathrm{H}$ balance also affects the selectivity in graphene oxide-based catalysts. It is 515 possible to suggest that there is a synergy between the active sites (sulfonic groups) and the 516 amount of oxygen groups remaining in the sulfonated reduced graphene oxides. 517 Oxygenated groups can serve as adsorption sites for reagents and products, promoting the 518 consecutive reaction of MTBG to DTBG and TTBG. In the case of graphene oxide, which 519 mostly contains only sulfonic groups on the surface and very few oxygenated groups -as in 
520 the case of $(\mathrm{GO}) \mathrm{R}_{\mathrm{Z}} \mathrm{S}$, a high conversion of glycerol can be generated, but the selectivity

521 obtained towards poly-substituted ethers could be low.

522

\section{4. Conclusion}

524 Sulfonated reduced graphene oxide has been obtained through different methods of

525 synthesis previously reported in the literature and then tested in the glycerol etherification

526 with tert-butyl alcohol. The results indicate that it is important to synthesize nanometric

527 graphene oxide and prior to acid functionalization, the reducing agent must be correctly

528 selected. In our study, the route that was favored was the reduction with ascorbic acid,

529 converting the process into a green synthesis by preventing the use of typical toxic reducing

530 agents such as hydrazine. The sulfonation using diazotization is an easy and effective route

531 to functionalize the reduced graphene oxide, since it generates a homogeneous dispersion in

532 the carbon skeleton. The results of activity of this type of catalysts, show better results than

533 those achieved with the reference catalyst Amberlyst ${ }^{\circledR}$ 15. The selectivity towards poly-

534 substituted ethers is influenced by the synergy between the remaining oxygenated species

535 after the reduction process and the grafted sulfonic groups. As far as recyclability is

536 concerned, these catalysts have shown to be stable and easily regenerable (through ethanol

537 washing), converting them into efficient solids in acid reactions in which the formation of

538 water as a by-product is observed, such as the glycerol etherification with tert-butyl

539 alcohol.

540

541 Acknowledgements 
542 C. Miranda thanks Colciencias for the financial support provided for doctoral formation 543 through the 617 convocation. The authors further acknowledge financial support from the 544 European Union (ERDF) and "Région Nouvelle Aquitaine".

545

546

547

548

549

550

551

552

553

554 References

555

556 [1] M. Pagliaro, R. Ciriminna, H. Kimura, M. Rossi and C. Della Pina, Angew. Chem. $557 \quad$ Int. Ed. Engl. 46 (2007) 4434-4440.

558 [2] C. Len and R. Luque, Sustain. Chem. Process. 2 (2014) 1-10.

559 [3] J. F. Izquierdo, M. Montiel, I. Palés, P. R. Outón, M. Galán, L. Jutglar, M. 560 Villarrubia, M. Izquierdo, M. P. Hermo and X. Ariza, Renew. Sust. Energ. Rev. 16 561

562 [4] M. Sutter, E. D. Silva, N. Duguet, Y. Raoul, E. Metay and M. Lemaire, Chem. Rev. 563 115 (2015) 8609-8651. 
564 [5] C. Cannilla, G. Bonura, L. Frusteri and F. Frusteri, Chem. Eng. J. 282 (2015) 187565193.

566 [6] C. Cannilla, G. Bonura, L. Frusteri and F. Frusteri, Cent. Eur. J. Chem. 12 (2014) $567 \quad 1248-1254$.

568 [7] L. Frusteri, C. Cannilla, G. Bonura, A. L. Chuvilin, S. Perathoner, G. Centi and F. $569 \quad$ Frusteri, Catal. Today. 277 (2016) 68-77.

570 [8] K. Klepáčová, D. Mravec, A. Kaszonyi. and M. Bajus, Appl. Catal., A, 328 (2007) $571 \quad 1-13$.

572 [9] J. A. Melero, G. Vicente, G. Morales, M. Paniagua, J. M. Moreno, R. Roldán, A. 573 Ezquerro and C. Pérez, Appl. Catal., A, 346 (2008) 44-51.

574 [10] R. S. Karinen and A. O. I. Krause, Appl. Catal. A, 306 (2006) 128-133.

575 [11] E. Vlad, C. S. Bildea and G. Bozga, ScientificWorldJournal, 2012 (2012) 180617.

576 [12] C. Cannilla, G. Bonura, L. Frusteri and F. Frusteri, Environ. Sci. Technol., 48 (2014) $577 \quad 6019-6026$.

578 [13] Theodore, E. and K.R. Edlund, Process and product relating to tertiary ethers, 5791934.

580 [14] K. Klepáčová, D. Mravec and M. Bajus, Appl. Catal., A, 294 (2005) 141-147.

581 [15] K. Y. Nandiwale, S. E. Patil and V. V. Bokade, Energy Technol. 2 (2014) 446-452. 
582

583

584

585

586

587

588

589

590

591

592

593

594

595

596

597

598

599

600

[16] C. Miranda, J. Urresta, H. Cruchade, A. Tran, M. Benghalem, A. Astafan, P. Gaudin, T. J. Daou, A. Ramírez, Y. Pouilloux, A. Sachse and L. Pinard, J. Catal., 365 (2018) 249-260.

[17] M. M. Antunes, P. A. Russo, P. V. Wiper, J. M. Veiga, M. Pillinger, L. Mafra, D. V. Evtuguin, N. Pinna and A. A. Valente, ChemSusChem, 7 (2014) 804-812.

[18] J. Janaun and N. Ellis, J. Appl. Sci., 10 (2010) 2633-2637.

[19] T. S. Galhardo, N. Simone, M. Gonçalves, F. C. A. Figueiredo, D. Mandelli and W. A. Carvalho, ACS Sus. Chem. Eng., 1 (2013) 1381-1389.

[20] J. Ji, G. Zhang, H. Chen, S. Wang, G. Zhang, F. Zhang and X. Fan, Chem. Sci. 2 (2011) 484-487.

[21] M. Brahmayya, S. A. Dai and S. Y. Suen, Sci. Rep. 7 (2017) 4675.

[22] L. Wang, D. Wang, S. Zhang and H. Tian, Catal. Sci. Technol. 3 (2013) 1194-1197.

[23] K. K. Praveen, K. Prashant, N. Ponnnekanti and L. J. Suman, Lett. Org. Chem. 15 (2018) 508-514.

[24] J. Zhou, Y. Wang, X. Guo, J. Mao and S. Zhang, Green Chem. 16 (2014) 46694679.

[25] N. I. Kovtyukhova, P. J. Ollivier, B. R. Martin, T. E. Mallouk, S. A. Chizhik, E. V. Buzaneva and A. D. Gorchinskiy, Chem. Mater. 11 (1999) 771-778.

[26] W. S. Hummers and R. E. Offeman, J. Am. Chem. Soc. 80 (1958) 1339-1339. 
601 [27] J. Zhang, H. Yang, G. Shen, P. Cheng, J. Zhang and S. Guo, Chem. Commun., $602 \quad 46(2010) 1112-1114$

603 [28] X. Mei and J. Ouyang, Carbon, 49 (2011) 5389-5397.

604 [29] N. Oger, Y. F. Lin, C. Labrugère, E. Le Grognec, F. Rataboul and F.-X. Felpin, 605 Carbon, 96 (2016) 342-350.

606 [30] A. T. Quitain, Y. Sumigawa, E. G. Mission, M. Sasaki, S. Assabumrungrat and T. $607 \quad$ Kida, Energy Fuels, 32 (2018) 3599-3607.

608 [31] K. Nakajima and M. Hara, ACS Catalysis, 2 (2012) 1296-1304.

609 [32] M. D. González, P. Salagre, M. Linares, R. García, D. Serrano and Y. Cesteros, $610 \quad$ Appl. Catal. A, 473 (2014) 75-82.

611 [33] X. Y. Liu, M. Huang, H. L. Ma, Z. Q. Zhang, J. M. Gao, Y. L. Zhu, X. J. Han and 612 X. Y. Guo, Molecules, 15 (2010) 7188-7196.

613 [34] R. Kunin, E. A. Meitzner, J. A. Oline, S. A. Fisher and N. Frisch, Ind. Eng. Chem. 614 Prod. Res. Dev. 1 (1962) 140-144.

615 [35] R. L. Whitby, V. M. Gun'ko, A. Korobeinyk, R. Busquets, A. B. Cundy, K. Laszlo, 616 J. Skubiszewska-Zieba, R. Leboda, E. Tombacz, I. Y. Toth, K. Kovacs and S. V. 617 Mikhalovsky, ACS Nano, 6 (2012) 3967-3973.

618 [36] B. Manoj and A. Kunjomana, Int. J. Electrochem. Sci., 7 (2012) 3127-3134. 
619 [37] S. Park, J. An, J. R. Potts, A. Velamakanni, S. Murali and R. S. Ruoff, Carbon, 49 $620 \quad$ (2011) 3019-3023.

621 [38] R. Saito, M. Hofmann, G. Dresselhaus, A. Jorio and M. S. Dresselhaus, Adv. Phys. $622 \quad 60(2011) 413-550$.

623 [39] S. S. Nanda, M. J. Kim, K. S. Yeom, S. S. A. An, H. Ju and D. K.Yi, TrAC, Trends $624 \quad$ Anal. Chem. 80 (2016) 125-131.

625 [40] S. Stankovich, D. A. Dikin, R. D. Piner, K. A. Kohlhaas, A. Kleinhammes, Y. Jia, 626 Y. Wu, S. T. Nguyen and R. S. Ruoff, Carbon, 45 (2007) 1558-1565.

627 [41] A. C. Ferrari and J. Robertson, Phys. Rev. B, 61 (2000) 14095-14107.

628 [42] S. Eigler and A. Hirsch, Angew. Chem. Int. Ed., 53 (2014) 7720-7738.

629 [43] S. Zhu, C. Chen, Y. Xue, J. Wu, J. Wang and W. Fan, ChemCatChem, 6 (2014) $630 \quad 3080-3083$.

631 [44] X. Gao, S. Zhu and Y. Li, Catal. Commun. 62 (2015) 48-51.

632 [45] G. Wang, B. Wang, J. Park, J. Yang, X. Shen and J. Yao, Carbon, 47 (2009) 68-72.

633 [46] M. Brahmayya, S. A. Dai and S.-Y. Suen, Sci Rep. 7 (2017) 4675.

634 [47] C. Hontoria-Lucas, A. J. López-Peinado, J. d. D. López-González, M. L. Rojas635 Cervantes and R. M. Martín-Aranda, Carbon, 33 (1995) 1585-1592.

636 [48] A. V. Nakhate and G. D. Yadav, ACS Sustainable Chem. Eng. 4 (2016) 1963-1973. 
637 [49] M. Cordoba, C. Miranda, C. Lederhos, F. Coloma-Pascual, A. Ardila, G. Fuentes, $638 \quad$ Y. Pouilloux and A. Ramírez, Catalysts, 7 (2017) 384.

639 [50] F. Frusteri, F. Arena, G. Bonura, C. Cannilla, L. Spadaro and O. Di Blasi, Appl. $640 \quad$ Catal., A, 367 (2009) 77-83.

641 [51] W. Kiatkittipong, P. Intaracharoen, N. Laosiripojana, C. Chaisuk, P. Praserthdam 642 and S. Assabumrungrat, Comput. Chem. Eng. 35 (2011) 2034-2043.

643 [52] M. Sharma, R. K. Wanchoo, and A. P. Toor, Ind. Eng. Chem. Res. 53 (2014) 2167$644 \quad 2174$

645 [53] M. Mirza-Aghayan, M. M. Tavana and R. Boukherroub, Ultrason. Sonochem. 29 $646 \quad$ (2016) 371-379.

647 [54] L. J. Cote, J. Kim, V. C. Tung, J. Luo, F. Kim and J. Huang, Pure Appl. Chem., 83 $648 \quad$ (2011) 95-110.

649 [55] S. Azizighannad and S. Mitra, Sci. Rep., 8 (2018) 1-8.

650 [56] P. M. Veiga, A. C. L. Gomes, C. O. Veloso and C. A. Henriques, Appl. Catal. A, $651 \quad 548(2017) 2-15$.

652 [57] M. D. González, Y. Cesteros and P. Salagre, Appl. Catal. A, 450 (2013) 178-188.

653

654

655

656 
661

662

663

664

665

666

667

668

669

670

671

672

\section{List of tables and figures}

674

675 Table 1. Textural and acidic properties of Amberlyst ${ }^{\circledR}$ 15, graphene oxide and sulfonated 676 reduced graphene oxide.

677

678 Table 2. Glycerol etherification with tert-butyl alcohol: conversion and selectivity after 10

$679 \mathrm{~h}$, initial activity $\left(\mathrm{A}_{0}\right)$ and TOF obtained on activated carbon, Amberlyst ${ }^{\circledR} 15$, GO and 680 sulfonated reduced graphene oxide. 
682 Figure 1. XRD patterns of graphite, preoxidated graphite, $(\mathrm{GO}),(\mathrm{GO}) \mathrm{R}_{\mathrm{A}},(\mathrm{GO}) \mathrm{R}_{\mathrm{H}}$ and $683(\mathrm{GO}) \mathrm{R}_{\mathrm{Z}} \mathrm{S}$.

684

685 Figure 2. Raman spectra of graphite, $(\mathrm{GO}),(\mathrm{GO}) \mathrm{R}_{\mathrm{H}}$, and $(\mathrm{GO}) \mathrm{R}_{\mathrm{A}}$.

686

687 Figure 3. SEM images of: a) graphite; b) (GO), c) $(\mathrm{GO}) \mathrm{R}_{\mathrm{A}}$; d) $(\mathrm{GO}) \mathrm{R}_{\mathrm{A}}-\mathrm{S}$.

688

689 Figure 4. Transmission electronic images of the samples and EDS mapping showing the 690 spatial distribution of $\mathrm{C}$ and $\mathrm{S}$ of $(\mathrm{GO}) \mathrm{R}_{\mathrm{H}^{-}} \mathrm{S}$ and $(\mathrm{GO}) \mathrm{R}_{\mathrm{A}^{-}} \mathrm{S}$.

691

692 Figure 5. XPS spectra for graphite, a); pre-oxidized graphite, b); (GO), c); (GO) $\left.\mathrm{R}_{\mathrm{H}}, \mathrm{d}\right)$; $\left.\left.693(\mathrm{GO}) \mathrm{R}_{\mathrm{A}}, \mathrm{e}\right) ;(\mathrm{GO}) \mathrm{R}_{\mathrm{Z}^{-}} \mathrm{S}, \mathrm{f}\right)$.

694 Figure 6. Atomic concentration (\%) determined by XPS of graphite, pre-oxidized graphite, $695(\mathrm{GO}),(\mathrm{GO}) \mathrm{R}_{\mathrm{H}},(\mathrm{GO}) \mathrm{R}_{\mathrm{A}}$ and $(\mathrm{GO}) \mathrm{R}_{\mathrm{Z}} \mathrm{S}$.

696

697 Figure 7. Kinetical study of (AC)-S, a), and (GO) $\left.\mathrm{R}_{\mathrm{A}}-\mathrm{S}, \mathrm{b}\right)$.

698

699 Figure 8. Glycerol conversion as a function of reaction time. (AC)-S, (AC) $\mathrm{R}_{\mathrm{H}} \mathrm{S}$ and 700 Amberlyst ${ }^{\circledR} 15$, a); Catalysts based on GO, b). Test carried out at $363 \mathrm{~K}, 1200 \mathrm{rpm}$, 701 autogenous pressure, 7,5\% of catalyst (referred to glycerol mass) and glycerol/tert-butyl 702 alcohol molar ratio of 0.25 .

703 
704 Figure 9. Correlation of the initial activity with the acidity of the catalysts based on GO,

$705 \quad$ AC and Amberlyst ${ }^{\circledR} 15$

706

707 Figure 10. Results of recycling experiments for $\left.(\mathrm{GO}) \mathrm{R}_{\mathrm{A}}-\mathrm{S}, \mathrm{a}\right)$ and $\left.(\mathrm{AC})-\mathrm{S}, \mathrm{b}\right)$.

708

709 Figure 11. Molar yields into MTBG, DTBG and TTBG as a function of glycerol 710 conversion for catalyst based on sulfonated reduced GO compared to A-15.

711

712

713

714

715

716

717

718

719

720

721 Table 1. Textural and acidic properties of Amberlyst ${ }^{\circledR} 15$, graphene oxide and sulfonated

722 reduced graphene oxide.

\begin{tabular}{|c|c|c|c|c|c|c|c|}
\hline \multirow[t]{2}{*}{ Catalyst } & \multirow{2}{*}{$\mathbf{S}_{B E T}$} & \multicolumn{3}{|c|}{ Elemental Analysis (\%) } & \multirow[t]{2}{*}{ Acidity $\left(\mathrm{mmol}\left[\mathrm{H}^{+}\right] \mathrm{g}^{-1}\right)$} & \multirow[t]{2}{*}{$\mathrm{C} / \mathrm{O}$ ratio } & \multirow{2}{*}{$\begin{array}{c}\text { S/C ratio } \\
\times 10^{-2} \\
\end{array}$} \\
\hline & & $\mathrm{C}$ & $\mathrm{O}$ & $\mathrm{S}$ & & & \\
\hline (AC) & 978 & 73.16 & 24.89 & 0.00 & 0.71 & 3.92 & - \\
\hline (AC)-S & 224 & 67.75 & 26.29 & 3.35 & $1.05(1.76)^{\mathrm{c}}$ & 3.44 & 1.85 \\
\hline$(\mathrm{AC}) \mathrm{R}_{\mathrm{H}}$ & 919 & 79.39 & 19.19 & 0.00 & -- & 5.52 & -- \\
\hline$(\mathrm{AC}) \mathrm{R}_{\mathrm{H}^{-}} \mathrm{S}$ & 163 & 68.70 & 25.33 & 3.94 & 1.23 & 3.62 & 2.15 \\
\hline A-15 & 53 & - & - & - & $2.37^{\mathrm{a}}$ & & \\
\hline Graphite & - & 97.70 & 2.30 & 0.00 & -- & $56.64^{\mathrm{b}}$ & -- \\
\hline
\end{tabular}




\begin{tabular}{cccccccc}
\hline$(\mathrm{GO})$ & 5 & 35.47 & 60.29 & 1.45 & $0.45(0.51)^{\mathrm{c}}$ & 0.78 & 1.53 \\
$(\mathrm{GO})-\mathrm{S}$ & & 46.99 & 47.27 & 2.37 & $0.74(0.70)^{\mathrm{c}}$ & 1.33 & 1.89 \\
$(\mathrm{GO}) \mathrm{R}_{\mathrm{H}}$ & 22 & 66.40 & 31.40 & 0.00 & -- & 2.82 & -- \\
$(\mathrm{GO}) \mathrm{R}_{\mathrm{Z}}$ & & 93.16 & 6.86 & 0.00 & -- & 18.1 & -- \\
$(\mathrm{GO}) \mathrm{R}_{\mathrm{A}}$ & 14 & 70.96 & 27.59 & 0.00 & - & 3.43 & - \\
$(\mathrm{GO}) \mathrm{R}_{\mathrm{H}}-\mathrm{S}$ & 11 & 60.14 & 34.82 & 3.29 & $1.03(1.05)^{\mathrm{c}}$ & 2.30 & 2.05 \\
$(\mathrm{GO}) \mathrm{R}_{\mathrm{Z}}-\mathrm{S}$ & 10 & 85.13 & 10.15 & 4.72 & $1.48(1.37)^{\mathrm{c}}$ & 11.2 & 2.08 \\
$(\mathrm{GO}) \mathrm{R}_{\mathrm{A}}-\mathrm{S}$ & 7 & 55.86 & 35.01 & 6.88 & $2.15(2.12)^{\mathrm{c}}$ & 2.13 & 4.62 \\
\hline
\end{tabular}

723

${ }^{\mathrm{a}}$ Measured by Pyr-IR adsorption. ${ }^{\mathrm{b}}$ Measured by XPS. ${ }^{\mathrm{c}}$ In parenthesis = acidity determined by Boehm titration.

724

725

726

727

728

729

730

731

732

733

734

735

736

737

738

739 Table 2. Glycerol etherification with tert-butyl alcohol: conversion and selectivity after 10

$740 \mathrm{~h}$, initial activity $\left(\mathrm{A}^{0}\right)$ and TOF obtained on Amberlyst ${ }^{\circledR} 15$ (A-15), activated carbon,

graphene oxide and sulfonated reduced graphene oxide.

\begin{tabular}{|c|c|c|c|c|c|}
\hline \multirow[t]{2}{*}{ Catalyst } & \multirow[t]{2}{*}{ Conv. (\%) } & \multicolumn{2}{|c|}{ Selectivity (\%) } & \multirow{2}{*}{$\begin{array}{c}\mathrm{A}_{\text {glycerol }}^{0} \\
\left(\mathrm{~mol} \mathrm{~h}^{-1} \mathrm{~g}^{-1}\right) \times \mathbf{1 0}^{\mathbf{4}}\end{array}$} & \multirow{2}{*}{$\begin{array}{c}\text { TOF }^{\mathrm{a}} \\
\left(\mathrm{h}^{-1}\right) \times \mathbf{1 0} \mathbf{1 0}^{\mathbf{2}}\end{array}$} \\
\hline & & MTBG & DTBG & & \\
\hline$(\mathrm{AC})$ & 0 & 0 & $\overline{0}$ & $\overline{--}$ & -- \\
\hline$(\mathrm{AC})-\mathrm{S}$ & 35 & 80 & 20 & 1.45 & 14 \\
\hline$(\mathrm{AC}) \mathrm{R}_{\mathrm{H}}-\mathrm{S}$ & 31 & 86 & 14 & 1.28 & 10 \\
\hline A-15 & 64 & 75 & $25(0.3)$ & 15.00 & 63 \\
\hline Graphite & 0 & 0 & 0 & -- & -- \\
\hline (GO) & 19 & 100 & 0 & 5.00 & 111 \\
\hline (GO)-S & 50 & 78 & $22(0.2)$ & 10.53 & 202 \\
\hline
\end{tabular}


742

743

744

745

746

747

748

\begin{tabular}{llll|lc}
$(\mathrm{GO}) \mathrm{R}_{\mathrm{H}}-\mathrm{S}$ & 73 & 71 & $29(0.7)$ & 14.02 & 107 \\
$(\mathrm{GO}) \mathrm{R}_{\mathrm{Z}}-\mathrm{S}$ & 76 & 88 & $12(0.1)$ & 12.71 & 194 \\
$(\mathrm{GO}) \mathrm{R}_{\mathrm{A}}-\mathrm{S}$ & 77 & 73 & $27(0.5)$ & 15.89 & 74
\end{tabular}

Reaction conditions: $7.5 \mathrm{wt} . \%$ of catalyst (referred to glycerol mass), glycerol/tert-butyl alcohol molar ratio $=0.25$, reaction temperature $=363 \mathrm{~K}$, reaction time $=10 \mathrm{~h}$, stirring $=1200 \mathrm{rpm}$. MTBG: glycerol mono-ethers; DTBG: glycerol $d i$-ethers (glycerol tri-ether in parenthesis). ${ }^{a}$ Turnover frequency per Brønsted acid sites. 48 


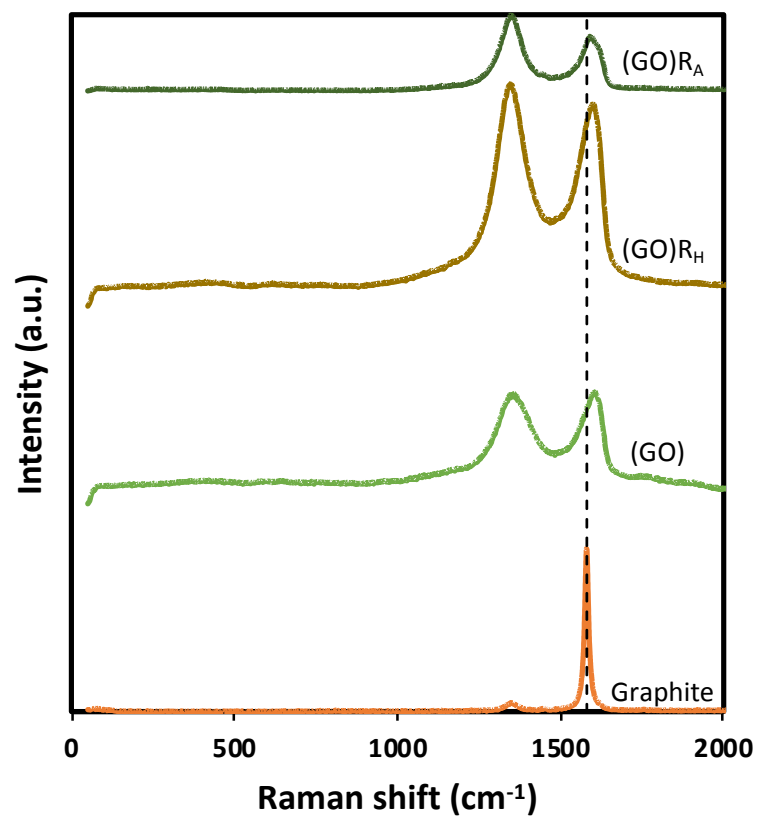

756

Figure 2. Raman spectra of graphite, $(\mathrm{GO}),(\mathrm{GO}) \mathrm{R}_{\mathrm{H}}$ and $(\mathrm{GO}) \mathrm{R}_{\mathrm{A}}$.

757

758

759

760

761

762

763

764 

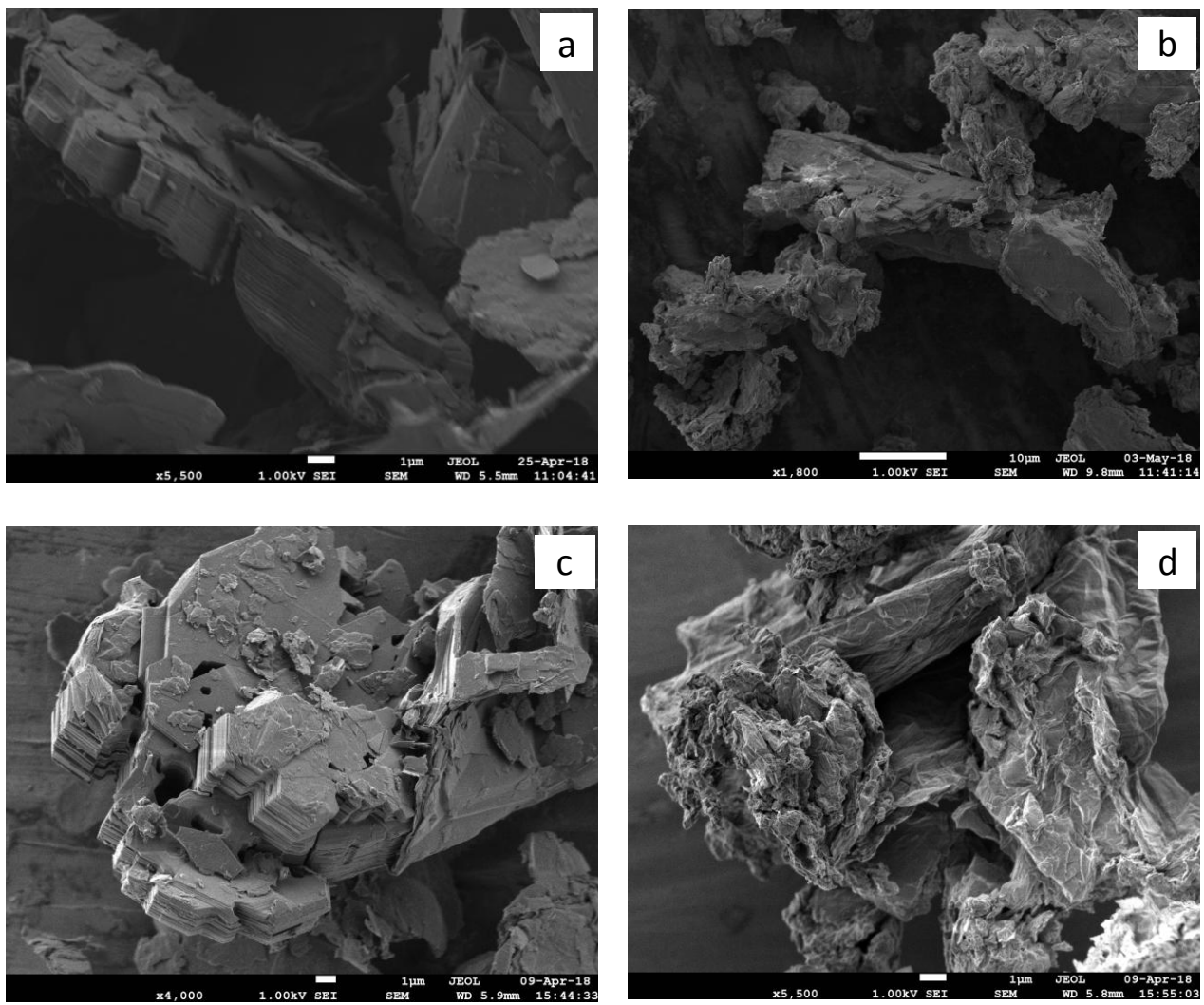

Figure 3. SEM images of: a) graphite; b) $(\mathrm{GO})$, c) $(\mathrm{GO}) \mathrm{R}_{\mathrm{A}}$; d) $(\mathrm{GO}) \mathrm{R}_{\mathrm{A}}-\mathrm{S}$

766

767

768

769

770

771

772

773

774

775

776 

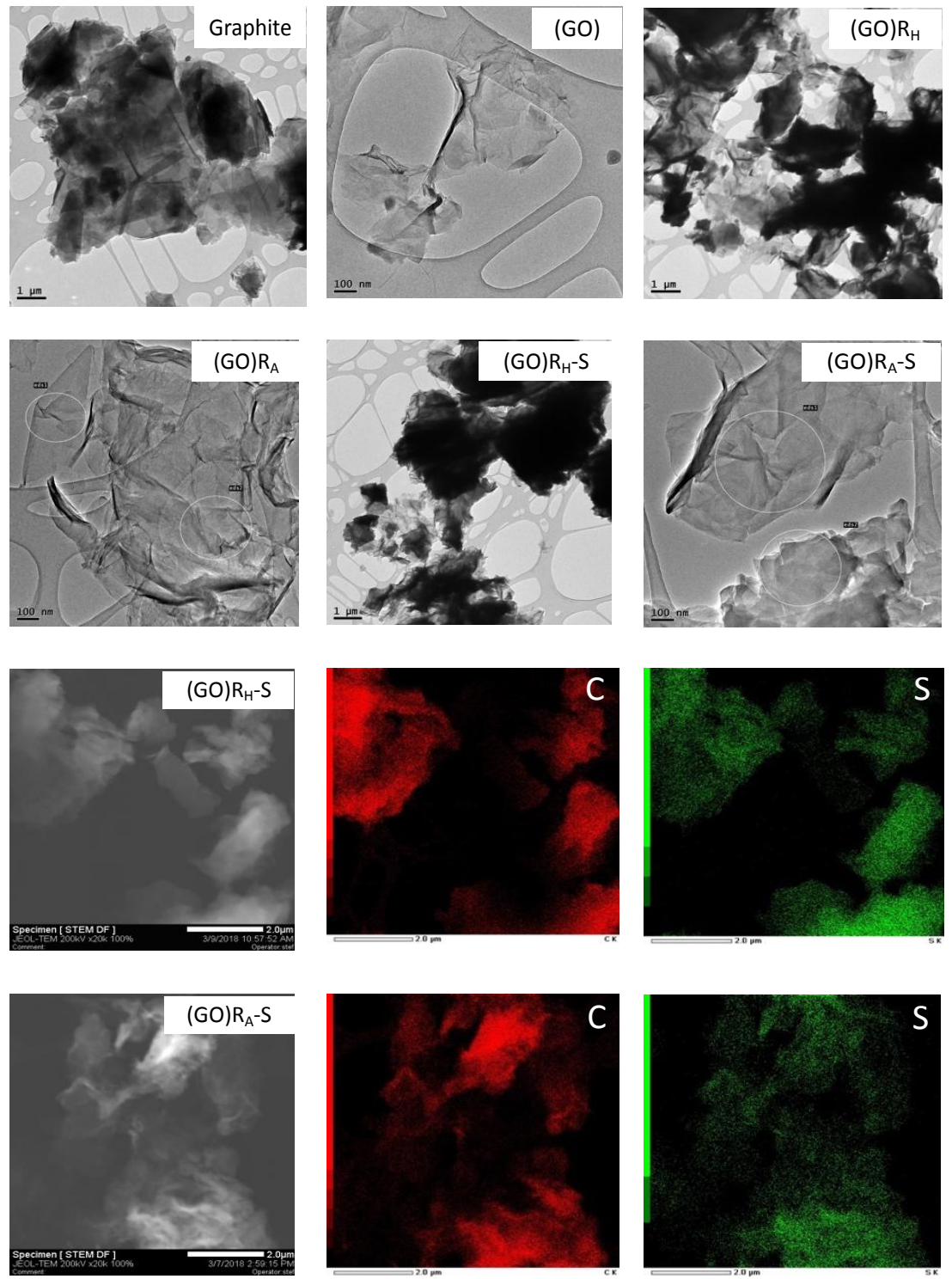

777 Figure 4. Transmission electronic images of the samples and EDS mapping showing the spatial distribution of $\mathrm{C}$ and $\mathrm{S}$ of $(\mathrm{GO}) \mathrm{R}_{\mathrm{H}^{-}} \mathrm{S}$ and $(\mathrm{GO}) \mathrm{R}_{\mathrm{A}}-\mathrm{S}$.

779 

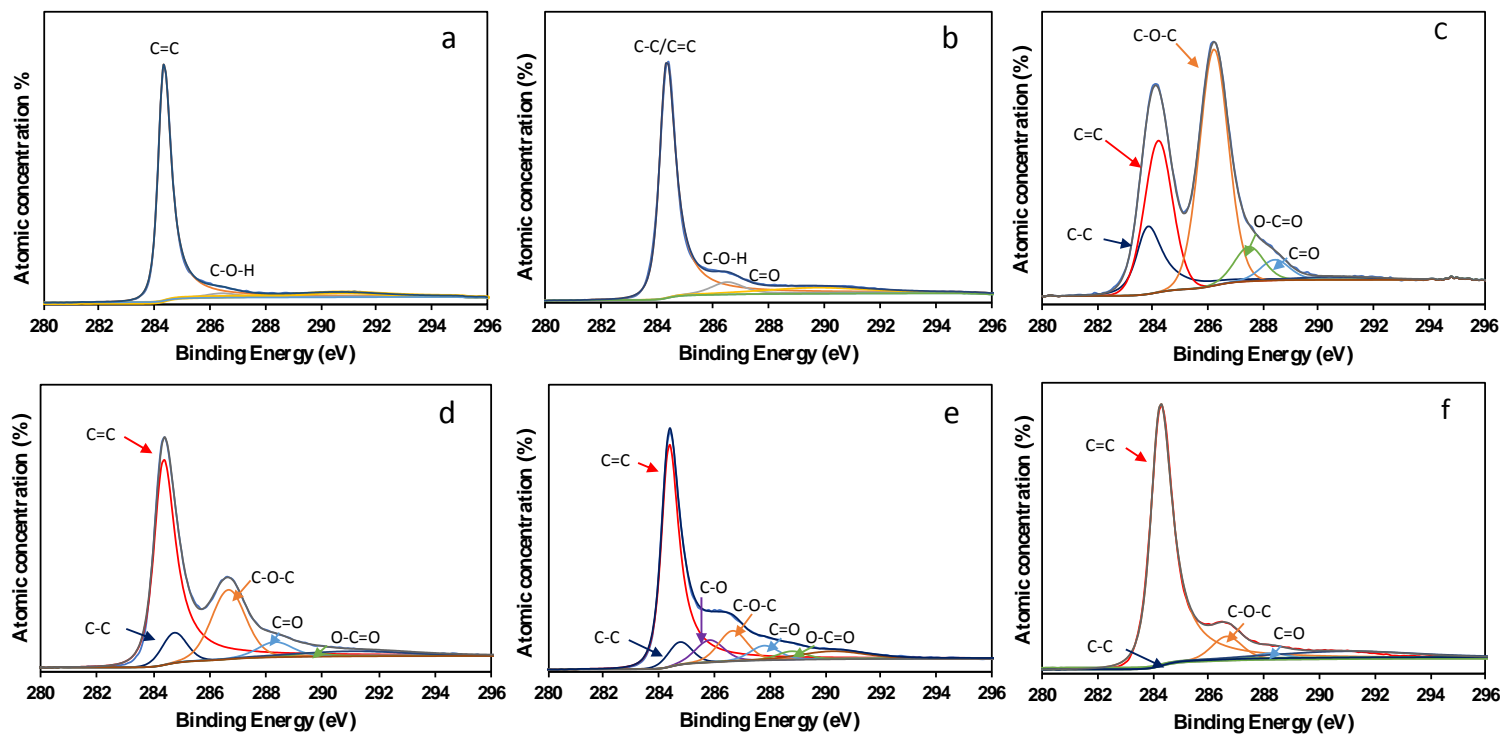

Figure 5. XPS spectra for graphite, a); pre-oxidized graphite, b); (GO), c); (GO) $\left.R_{H}, d\right)$;

$\left.\left.(\mathrm{GO}) \mathrm{R}_{\mathrm{A}}, \mathrm{e}\right) ;(\mathrm{GO}) \mathrm{R}_{\mathrm{Z}} \mathrm{S}, \mathrm{f}\right)$. 


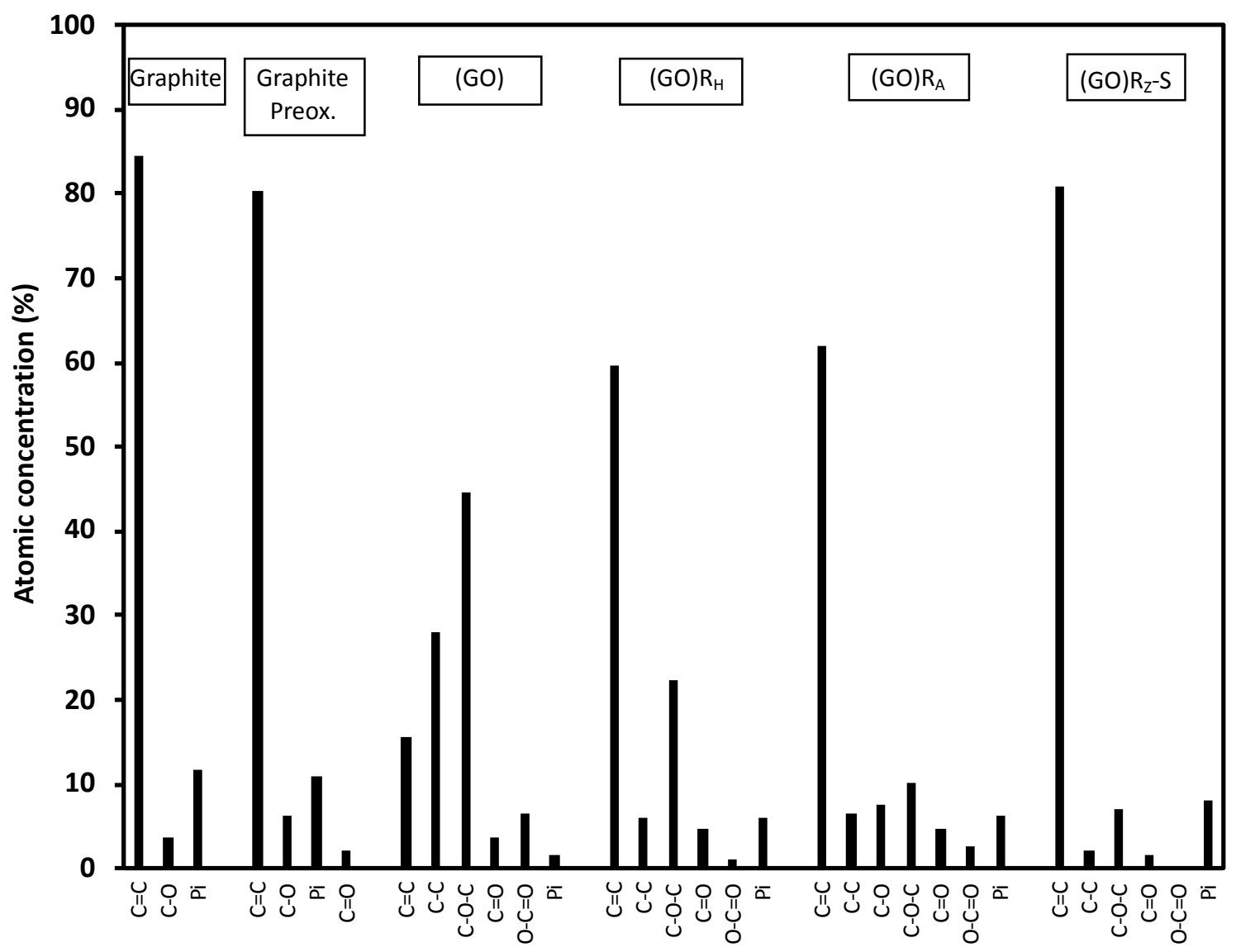

797 Figure 6. Atomic concentration (\%) determined by XPS of graphite, pre-oxidized graphite, $(\mathrm{GO}),(\mathrm{GO}) \mathrm{R}_{\mathrm{H}},(\mathrm{GO}) \mathrm{R}_{\mathrm{A}}$ and $(\mathrm{GO}) \mathrm{R}_{\mathrm{Z}}-\mathrm{S}$.

799

800

801

802
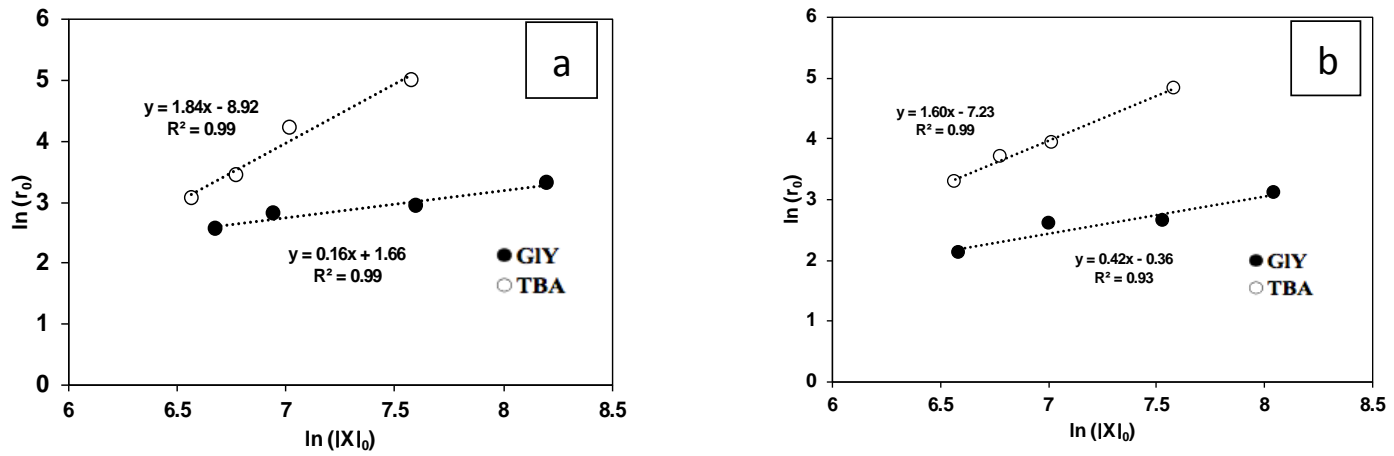
804

805

806

807

808

809

810

811

812

813

814

815

816

817

818

819

820

821 

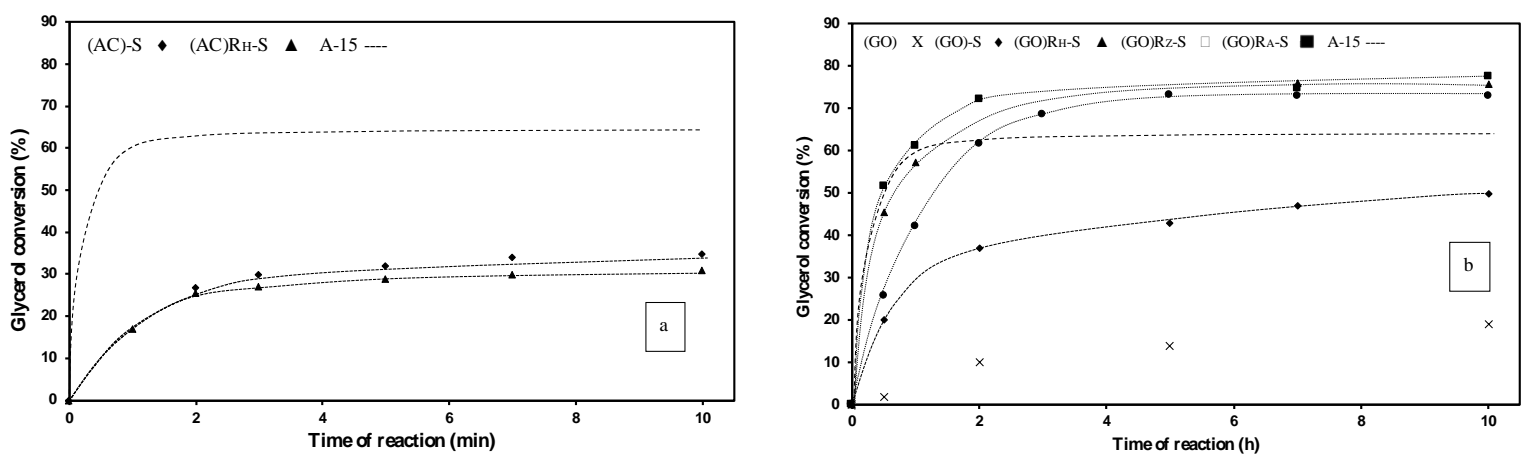

823 Figure 8. Glycerol conversion as a function of reaction time. (AC)-S, (AC) $\mathrm{R}_{\mathrm{H}^{-}} \mathrm{S}$ and

$824 \quad$ Amberlyst $^{\circledR} 15$ (A-15), a); Catalysts based on (GO), b). Test carried out at $363 \mathrm{~K}, 1200$

$825 \mathrm{rpm}$, autogenous pressure, 7,5\% of catalyst (referred to glycerol mass) and glycerol/tert- 


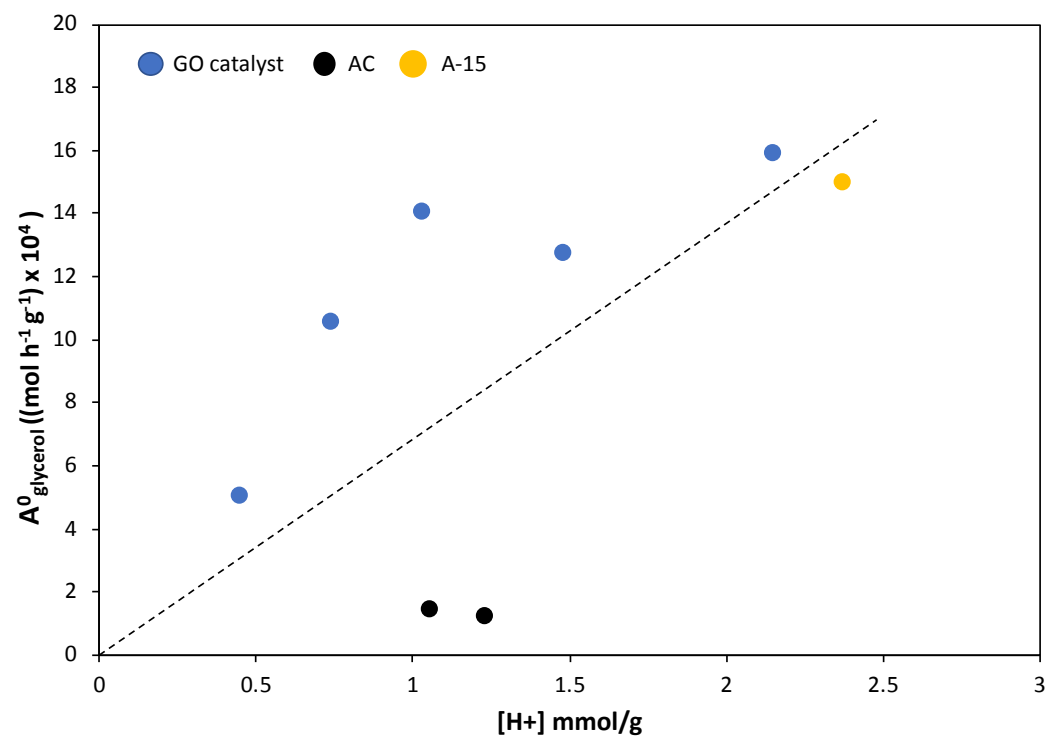

835 Figure 9. Correlation of the initial activity with the acidity of the catalysts based on GO, 

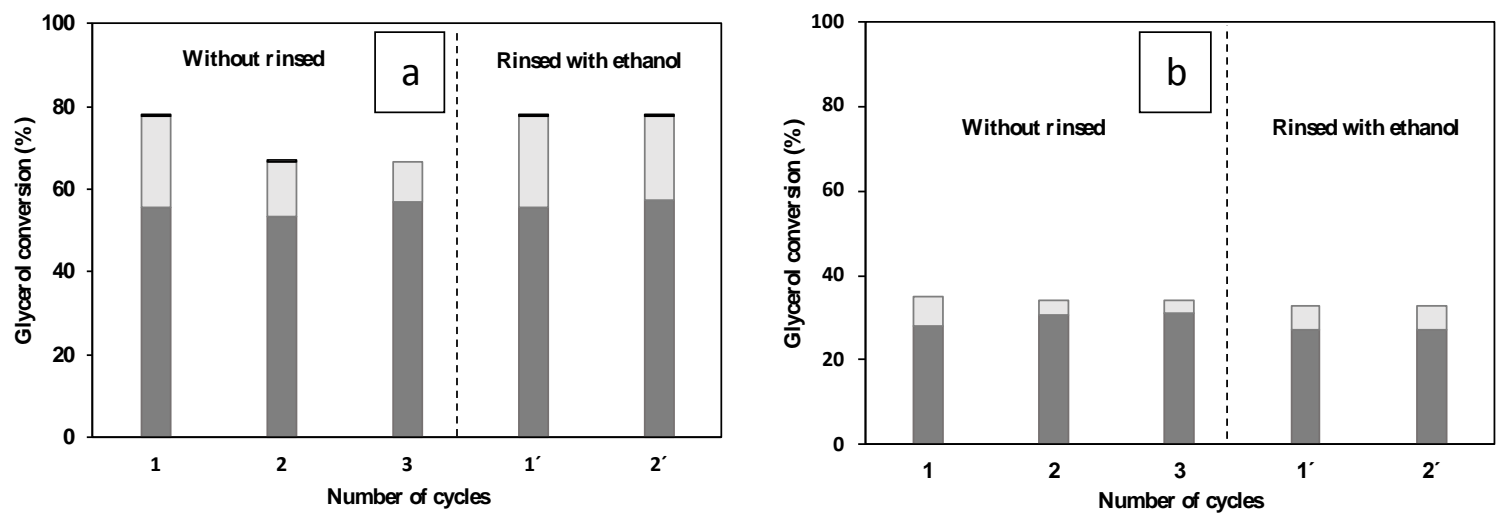

Figure 10. Results of recycling experiments for $(\mathrm{GO}) \mathrm{R}_{\mathrm{A}}-\mathrm{S}$, a) and (CA)-S, b). 


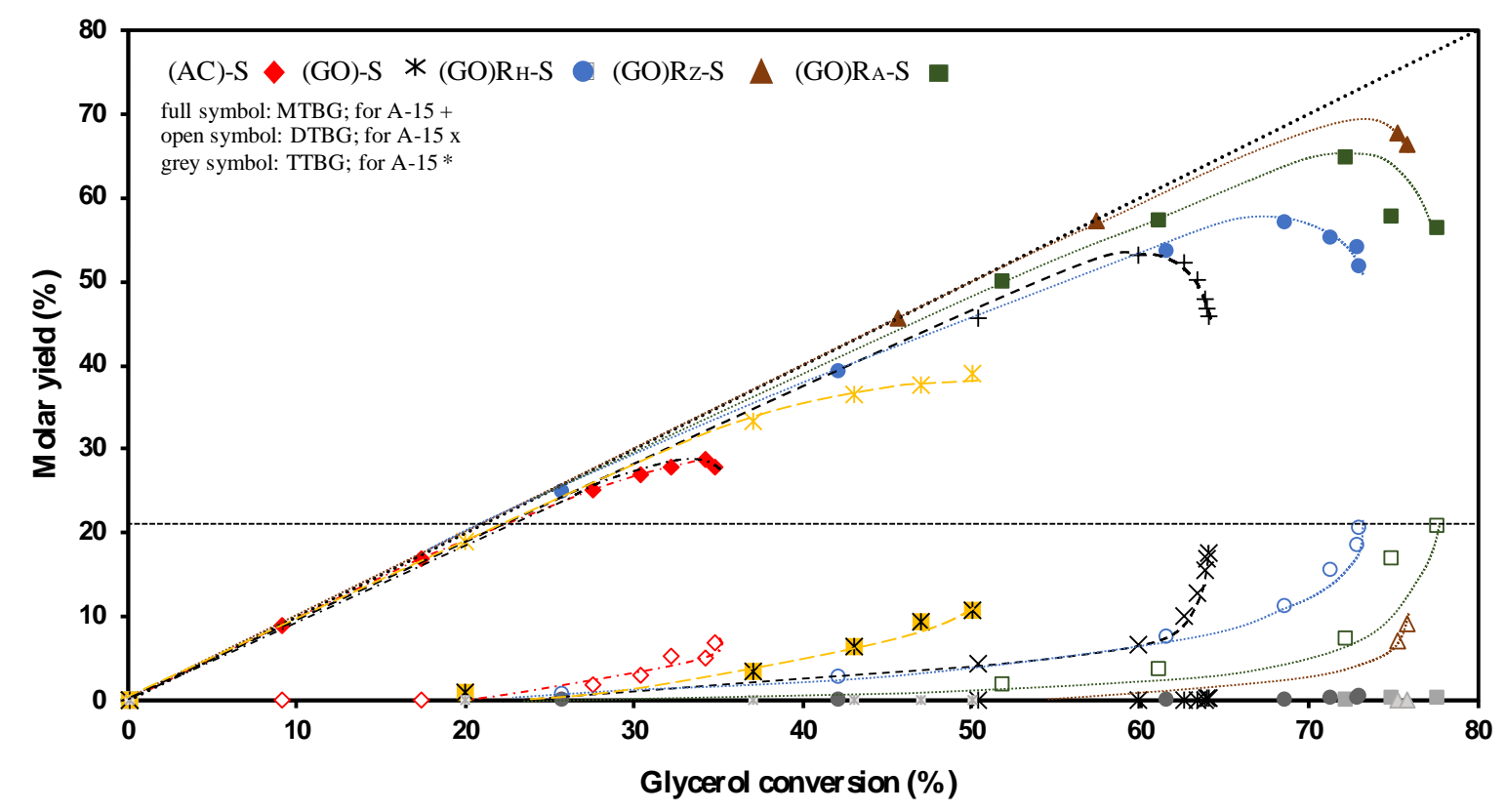

Figure 11. Molar yields into MTBG, DTBG and TTBG as a function of glycerol

861 conversion for catalyst based on sulfonated reduced GO, compared to A-15 and (AC)-S. 


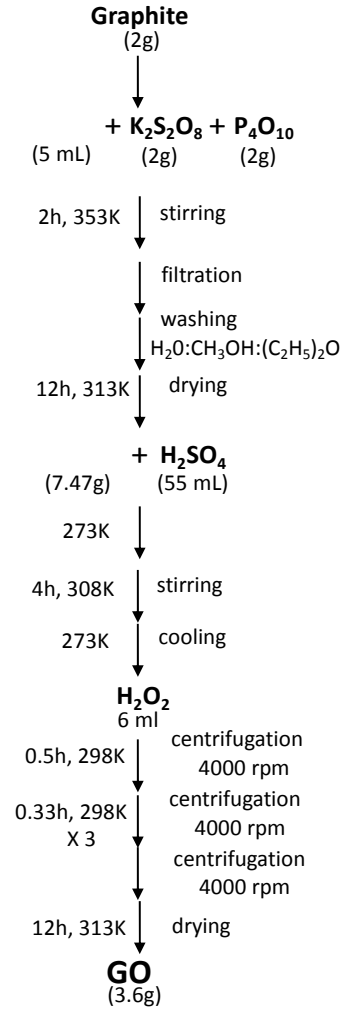

Figure S1. Diagram of synthesis of the graphene oxide. 


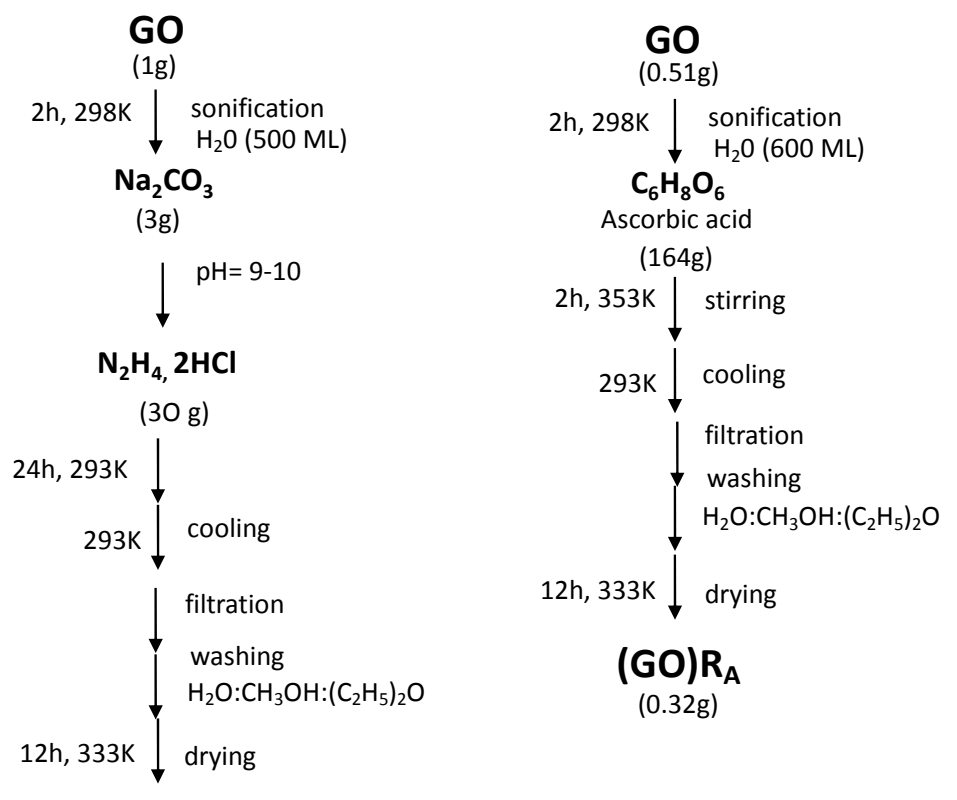

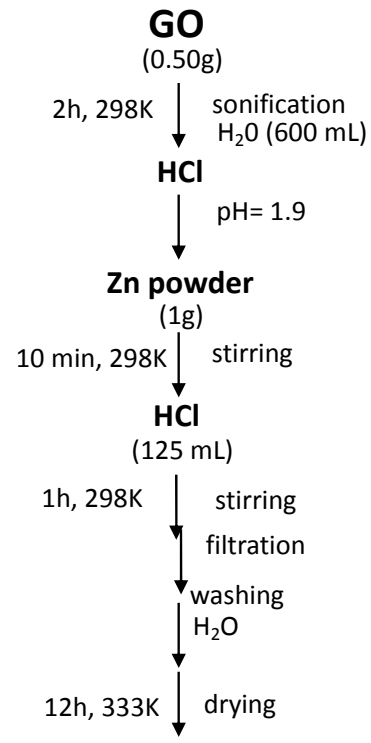

$(\mathbf{G O}) \mathbf{R}_{\mathbf{Z}}$

Figure S2. Diagram of synthesis of the reduced graphene oxide.

\section{Carbon material}

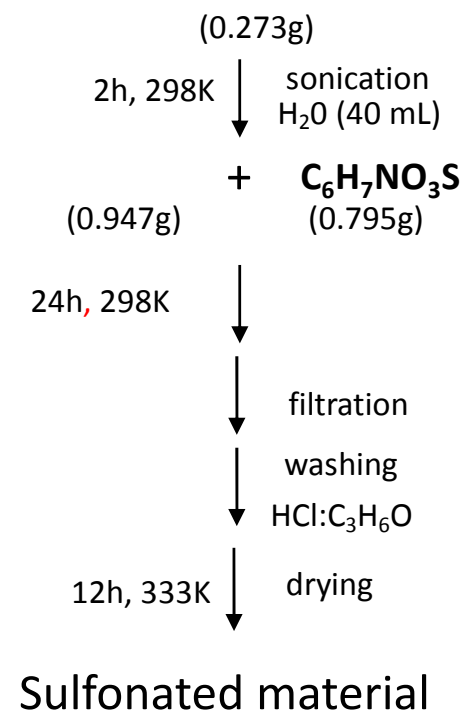

Figure S3. Diagram of synthesis of the sulfonated reduced graphene oxide. 
886

887

888

889

890

891

892

893

894

895

896 897 show overall less than $35 \%$ weight loss in the same temperature range. A first mass loss of

$8984.4 \%$ at around $373 \mathrm{~K}$ was attributed to volatiles desorption, mainly moisture. A second

Figure S4. TGA pattern of $(\mathrm{GO}) \mathrm{R}_{\mathrm{A}} \mathrm{S},(\mathrm{GO})$ and A-15.

Thermal stability study was carried out. Figure $\mathbf{S 4}$ compares the TGA curves of Amberlyst $^{\circledR} 15,(\mathrm{GO})$ and $(\mathrm{GO}) \mathrm{R}_{\mathrm{A}}-\mathrm{S}$. The overall weight loss of $64.5 \%$ for GO occurs in three successive steps. The first one is a steady weight loss of $7.7 \%$ attributed to the vaporization of adsorbed water molecules and occurs at around $393 \mathrm{~K}$. Then a rapid loss of $20 \%$ due to the decomposition of the oxygen-containing functional groups such as hydroxyl, epoxy, carbonyl, and carboxyl groups in the temperature range of 393-473 K. Finally, a weight loss of $36.8 \%$ that can be attributed to the combustion of the carbon skeleton is observed in the temperature range of $273-1163 \mathrm{~K}^{1}$. TGA curve for (GO) $\mathrm{R}_{\mathrm{A}}-\mathrm{S}$ 899 weight loss of $11.8 \%$ at around $648 \mathrm{~K}$ that can be attributed to the decomposition of




900 remnants oxygen groups (hydroxyl, epoxy, carbonyl, and carboxyl). The weight loss in the 901 temperature range 648-1163 K can be attributed to decomposition of sulfonated groups [1]. 902 The degradation of Amberlyst ${ }^{\circledR} 15$ proceeds in three steps: dehydration at $403 \mathrm{~K}$, 903 desulfonation at 508-603 K and oxidation of polymer at 603-828 K, representing a weight 904 loss of $60.7 \%$ at $873 \mathrm{~K}$. These results suggest that the $(\mathrm{GO}) \mathrm{R}_{\mathrm{A}}-\mathrm{S}$ is more thermally stable 905 than the reference catalyst Amberlyst ${ }^{\circledR}$ 15, which allows its use in acid reactions at 906 temperatures in which the A-15 can not be used.

907

908

909 [1] F. Liu, J. Sun, L. Zhu, X. Meng, C. Qi and F.-S. Xiao, J. Mater. Chem., 2012, 22, $910 \quad 5495-5502$.

911

912

913

914 